\title{
LIQUIDACIÓN DE LAS ASEGURADORAS DE RIESGOS DEL TRABAJO. NORMATIVA Y CRITERIOS JURISPRUDENCIALES EN CÓRDOBA
}

\author{
Silvia Kiatkovski ${ }^{1}$, Nicolás Francisco Niewolski Cesca², \\ Guillermo Joselín Cerda López ${ }^{3}$
}

Sumario: I. El fondo de reserva. II. Financiamiento del fondo de reserva. III. ¿A partir de cuándo debe responder el fondo de reserva? IV. La gerenciadora. V. ¿Quién resulta obligado al pago frente al trabajador en los procesos judiciales contra una ART liquidada? VI. La resolución 396/2020. VII. Intereses. VIII Los intereses en la jurisprudencia de la provincia de Córdoba. IX. Las costas ¿Forman parte de los conceptos integrativos de la eventual condena? X. Costas: Evolución de la jurisprudencia del TSJ y de la CUT de Córdoba (2015/2021). XI. ¿Y ahora qué? Los criterios de la Cámara del trabajo luego del dictado de "Monzón" y "Rosales" por el TSJ. La liquidación de ART Liderar. XII. EI TSJ y la inconstitucionalidad del decreto 1022/17. XIII. Cámara del Trabajo de Córdoba. XIV. Conclusiones.

Resumen: El presente informe resume la ponencia efectuada en la reunión plenaria de la Sala de Derecho Laboral y Procesal Laboral de la Universidad Blas Pascal del 7 de junio de 2021, a la que fueramos generosamente invitados por los Dres. Ricardo Francisco Seco y Edder Hernán Piazza. El fondo de reserva fue creado por la ley 24.557 para afrontar con sus recursos las prestaciones impagas de una ART en liquidación. Su reglamentación ha generado múltiples conflictos interpretativos que se traslucen en la jurisprudencia. Se abordarán en el presente, a partir de la jurisprudencia cordobesa, los criterios a la hora de determinar el obligado al pago y el alcance de las prestaciones. Asimismo, se reseñarán los criterios jurisprudenciales tanto de la Cámara Única del Trabajo como del TSJ, con relación a los intereses aplicables cuando interviene el fondo; así como los precedentes vinculados a las costas de los procesos judiciales contra una ART liquidada desde el año 2015 a la actualidad, con especial consideración al decreto 1022/17.

Palabras clave: ART liquidada. Fondo de reserva. Gerenciadora. Costas. Intereses

\footnotetext{
1 Abogada (UNC), Especialista en Derecho del Trabajo (UNC - UCC - UNL), Prosecretaria del Juzgado de Conciliación y del Trabajo de Octava Nominación de Córdoba.

2 Abogado (UNC), Magister en Derecho Empresario (U. Austral), Maestrando en Administración de Empresas (U. Siglo XXI).

3 Abogado (UNC), Magíster en Derecho y Argumentación (UNC), Especialista en Derecho del Trabajo (UNC-UCC-UNL), Prosecretario en la Secretaría Laboral del TSJ de Córdoba.
} 


\section{I.- El fondo de reserva}

La ley 24.557 (LRT) regula dos fondos especiales: el fondo de garantía y el fondo de reserva (FdR). Ambos buscan resguardar situaciones de insolvencia que se presentan en el ámbito de aplicación de esta ley. Resulta necesario diferenciarlos:

El art. 29 de la LRT establece que en caso de insolvencia patrimonial del empleador no asegurado o autoasegurado, demostrada sumariamente dicha insolvencia, será el fondo de garantía, a cargo de la Superintendencia de Riesgos del Trabajo (SRT) el que deberá responder.

El art. 34 de la LRT dispone la creación del FdR a cargo de la Superintendencia de Seguros de la Nación (SSN) que tiene como función abonar o contratar las prestaciones a cargo de la aseguradora de riesgos del trabajo (ART) que ésta dejara de abonar como consecuencia de su liquidación.

La norma deja claro que las prestaciones cubiertas son las que están a cargo de la ART liquidada. En consecuencia, no se incluyen en la cobertura del FdR obligaciones con sustento en un régimen de responsabilidad distinto a la LRT como las que tienen su fundamento en el derecho común.

En los procesos judiciales en contra de una ART liquidada, el trabajador damnificado -o sus derechohabientes- podrá hacerse de las sumas reclamadas, en caso de resultar acogidas, sin necesidad de comparecer judicialmente al proceso liquidatorio de la ART, ni de reclamar directamente a su empleador.

En la causa "Bravo4", el Dr. Giletta expresó que: "...La situación de liquidación de la Aseguradora... no tiene como respuesta normativa la apertura de la responsabilidad directa del empleador (aspecto claramente opinable desde el marco constitucional), sino que se dispone que las prestaciones serán asumidas por el fondo de reserva administrado por la SSN, sin ninguna restricción, subsistiendo entonces la indemnidad patrimonial de los empleadores que estaban asegurados por la compañía liquidada".

De este modo, el sistema reparatorio mantiene la responsabilidad fuera del ámbito patrimonial del empleador.

\section{Financiamiento del fondo de reserva}

El financiamiento del FdR surge del art. 34 de la ley de riesgos del trabajo que tiene dos vertientes principales: a) una porción de las primas que abonan las empresas a las ART, y b) el remanente del patrimonio de las aseguradoras liquidadas.

El decreto 1022/17 elevó el porcentaje de las primas recaudadas por las aseguradoras que debe ser transferido al fondo, el que pasó del 8 por mil al 15 por mil.

En cuanto al patrimonio remanente de las aseguradoras liquidadas, al asumir el FdR los principales pasivos que pudiera haber tenido la entidad en liquidación, los fondos restantes, luego de agotado el proceso liquidatorio, constituye la segunda fuente de financiamiento en importancia. 
El dinero aportado al FdR puede ser invertido en depósitos a plazo fijo en entidades financieras autorizadas para funcionar por el BCRA; asimismo puede ser utilizado para la compra de títulos de deuda, y eventualmente, para efectuar adelantos transitorios al fondo de garantía.

En cuanto a los egresos que debe afrontar el FdR, el principal lo constituyen las "prestaciones dinerarias" que deba afrontar la aseguradora liquidada. Asimismo, se abordará en el presente trabajo los accesorios constituidos por las costas y los intereses.

Según los últimos datos disponibles, correspondientes al ejercicio 2019, el patrimonio del FdR ascendía a \$11.070.333.735,625 habiendo crecido en dicho período en \$ 4.766.517.412,15.

Analizados los estados contables se aprecia que durante dicho período la ratio ingresos/ egresos fue de 5,64; es decir que por cada peso que abonó el fondo recibió \$ 5,64.

\section{INGRESOS Vs EGRESOS}



Ilustración 1 Datos obtenidos en base a balances oficiales publicados por la SSN en su web oficial.

Se aprecia que el estado financiero del FdR presenta índices de solvencia y liquidez robustos. En efecto, luego de la sanción de resolución conjunta SRT 233/2004 y SSN 29.773/2004 en adelante res. con. y del decreto 1022/17, los egresos del FdR se han visto sustancialmente reducidos en relación a los ingresos.

\section{III. ¿A partir de cuándo debe responder el fondo de reserva?}

La cobertura del fondo creado por el mencionado art. 34 de la LRT recién opera con la liquidación judicial de la ART (art. 1, resolución 28.117/2001 de la SSN). Esto trae el inconveniente de que en el lapso de tiempo que transcurre entre que se inicia el proceso de liquidación de la ART en la fase administrativa (con la revocación de la autorización para funcionar por parte de la SSN y SRT y la apertura del proceso liquidatorio) y el momento 
en que se abre la liquidación judicial (una vez firme dicha decisión administrativa que es recurrible ante la Cámara Nacional en lo Comercial) no se cuenta con la cobertura del FDr.

\section{La gerenciadora}

Una vez abierta la liquidación judicial de la ART, las prestaciones que la LRT pone a cargo del fondo de reserva no son otorgadas directamente por la SSN sino que las brinda una ART contratada como gerenciadora. En la resolución 28.117/2001 se justifica la conveniencia de dicha contratación porque "la estructura de esta Superintendencia como ente administrativo de control no se condice con las necesidades y/o urgencias de los casos que deben ser atendidos por el citado fondo".

Dicha resolución 28.117/2001 aprueba el reglamento para la intervención del fondo de reserva de la LRT (art. 34, LRT) en el otorgamiento de las prestaciones por medio de una ART contratada. ${ }^{6}$

\section{V. ¿Quién resulta obligado al pago frente al trabajador en los procesos judiciales contra una ART liquidada?}

Hemos visto que ante la liquidación de la ART existe un FdR que administra la SSN para afrontar con sus recursos las prestaciones impagas frente al trabajador. Y también vimos que la reglamentación introdujo un nuevo sujeto que no estaba previsto en la ley: la gerenciadora.

A continuación, vamos a analizar en la jurisprudencia provincial quien resulta obligado al pago frente al trabajador en los casos de liquidación de la ART contratada. En primer lugar, se expone el criterio de la Sala Laboral del Tribunal Superior de Justicia (TSJ); y, en segundo lugar, el de las Cámaras del Trabajo.

\section{A. Jurisprudencia del Tribunal Superior de Justicia}

Las primeras ART liquidadas fueron Luz ART SA y Responsabilidad Patronal ART SA. AIgunos tribunales resolvían condenar a la aseguradora liquidada. Recurridas estas sentencias, en el año 2015, el TSJ dictó una serie de fallos donde determinó que la obligada al pago frente al trabajador era "Prevención ART SA como mandataria de la Superintendencia de Seguros de la Nación que es administradora del fondo de reserva del art. 34, inc. $1^{\circ}$, de la LRT".

En "Soria" el máximo tribunal afirmó: "decretada la liquidación de la accionada "Luz A.R.T. $S A^{\prime \prime} y$, en consecuencia, su imposibilidad de contratar al amparo del régimen de la ley $N^{\circ}$ 24.557 no debió ser condenada. Cesó en su actividad el 29/09/06 por Res. N 31.355 y la Superintendencia la despojó de la correspondiente autorización por Res. N 1214/06 del 24/11/06.

En tales condiciones, la ley de riesgos del trabajo crea un fondo de reserva (art. 34), administrado por la S.R.T., delegando su participación en las causas en "Prevención ART SA" la que tomó intervención en autos. Corresponde que el capital, los intereses indicados y las costas deberán ser abonados por "Prevención ART SA" como mandataria de la Superintendencia de Seguros de la Nación que es administradora del fondo de reserva del art. 34 inc. $1^{\circ}$ LRT."

\footnotetext{
6 En el art. 4 establece que "la ART Contratada deberá brindar las prestaciones conforme las pautas establecidas en la normativa de Riesgos del Trabajo vigente, quedando sometida a la supervisión de los dos entes de contralor del Sistema de Riesgos del Trabajo: SUPERINTENDENCIA DE SEGUROS DE LA NACION y SUPERINTENDENCIA DE RIESGOS DEL TRABAJO, en orden a sus respectivas facultades. La ART Contratada está obligada a dar cumplimiento a todas las normativas que se refieren al control de oportunidad y calidad de prestaciones en especie emanadas de la SUPERINTENDENCIA DE RIESGOS DEL TRABAJO.

7 TSJ, Córdoba, Sala Laboral, sent. N 2, 18/02/2015, "Soria c/ Luz ART SA"
} 
Exactamente el mismo criterio utiliza el TSJ en "Alvarez", entre otros.

En el año 2019 el TSJ mantuvo el mismo criterio respecto de la obligada al pago, en causas en las que, frente a la liquidación de ART Interacción SA, se había condenado a la Prevención ART SA (gerenciadora) y ésta cuestionaba el título en que fue condenada.

En "Rosales" ", Prevención ART SA recurre en casación alegando que la perdidosa en el pleito es "ART Interacción SA" y atento su liquidación, debió ordenarse el pago a la Superintendencia de Seguros de la Nación (SSN) como administradora del FdR del art. 34 LRT. Manifiesta que Prevención ART SA es simplemente la representante de la SSN, pero no es ni administradora ni gerenciadora -como erróneamente expresa el veredicto- pues no tiene siquiera facultad para abonar y luego ejercitar acción de reembolso. Y agrega que si Prevención debiera cumplir una condena y después requerir el reembolso y eventualmente el FdR careciera de recursos, su mandante no tendría posibilidad de recuperar lo invertido.

En "Rosales", el TSJ considera que el recurso es formalmente inadmisible. "En cuanto a la condena en su contra, el tribunal entendió que, ante la liquidación de la demandada -ART Interacción SA- y conforme al plexo jurídico atinente a la operatividad del fondo de reserva, debía condenarse a "Prevención ART SA" en su condición de representante y gerenciadora designada por la SSN, como administradora de las prestaciones de dicho fondo -sin perjuicio de las acciones de repetición. Frente a ello, no se advierte la importancia dirimente del planteo si, al comparecer y tras explicar el procedimiento que sigue a la liquidación de una aseguradora, invoca la resolución de la SSN N³9910/16 y aclara que dispuso la contratación de Prevención ART SA -precisamente-como "gerenciadora" del otorgamiento de las prestaciones a cargo del $F D R$, agregando que se extiende a los reclamos judiciales y prejudiciales. Luego, más allá de los términos empleados por el a quo y de la forma de efectivizar los beneficios respecto de los cuales no hay discusión que recaen en el FDR -sea con bienes propios y luego acción de reembolso o directamente con recursos del FDR-, no surge que la obligación que se le impuso sea en una calidad distinta a la que la interesada invocó al pedir participación a mérito de la cual se le acordó".

Este criterio es sostenido por el alto cuerpo en reiterados pronunciamientos dictados con posterioridad.

\section{B. Jurisprudencia de las Cámaras del Trabajo}

En los procesos judiciales contra una ART liquidada, no se observa un criterio unificado al resolver quién resulta obligado al pago. Analizando en las resoluciones de distintos tribunales a quién se condena, podemos hacer la siguiente clasificación a los fines de una mejor exposición:

\section{Condena al Estado Nacional}

En “Moriconi"m0 el Dr. Salomón, Vocal de la Cámara del Trabajo de Villa María, condena al Estado Nacional de la República Argentina (art. 35, CN), identificado en la entidad administrativa "Superintendencia de Seguros de la Nación" (en su carácter de administradora del fondo de reserva - LRT) al ser legalmente responsable de las acreencias debidas por la hoy liquidada "Interacción ART SA". Asimismo intima a Prevención ART SA, en su carác-

\footnotetext{
8 TSJ, Córdoba, Sala Laboral, sent. N 16, 04/03/2015, "Álvarez c/ Responsabilidad Patronal”.

9 TSJ, Córdoba, Sala Laboral, auto N ${ }^{\circ} 149,30 / 04 / 2019$, "Rosales c/ Interacción ART SA y otro".

10 Cámara del Trabajo, Villa María, sent. №631, 09/10/2017, “Moriconi c/ ART Interacción ART SA”, Dr. Marcelo José Salomón.
} 
ter de gerenciadora del pago de los créditos adeudados por Interacción ART SA, a realizar en tiempo y forma "las gestiones administrativas" para cancelar las indemnizaciones, debiendo informar de las mismas al tribunal bajo apercibimiento de imponer sanciones procesales por tales incumplimientos.

Para resolver en tal sentido brinda los siguientes argumentos:

- "fondo de reserva o fondo de garantía" no es otra cosa que un capital dinerario... gestionado administrativamente por la Superintendencia de Seguros de la Nación (en adelante SSN) dependiente del Ministerio de Finanzas.

- SSN no es en sí misma una persona jurídica pública estatal... que le permita constituirse en "un centro de imputación de derechos y obligaciones". A esta oficina administrativa judicialmente no se le puede asignar responsabilidades de pago, pues en sí misma no tiene tal facultad; por lo tanto corresponde determinar -en el organigrama administrativo estatal- cuál es el organismo público que debe asumir tal responsabilidad.

- Superintendencia de Seguros es un organismo administrativo del Ministerio de Finanzas de la Nación y éste a su vez una delegación funcional del poder ejecutivo nacional (art. 100, 101 y cc de la C.N.) según el mandato constitucional y legal de aplicación, es al Estado Nacional de la República Argentina (art. 35 C.N.) a quien debe imputarse el pago de las indemnizaciones que esta sentencia admite, en su caso a través de la delegación administrativa referenciada y para ser afrontados con especificidad de recursos económicos integrantes del fondo de reserva (art. 34 ley 24.557 y cc).

- A este tribunal no se le pasa por alto la comparecencia procesal en la causa de Prevención ART $S A$, invocando su rol de "gerenciadora", carácter que habría sido concedido por la referida entidad administrativa estatal (SSN). Independientemente de los esquemas administrativos y de gestión que la SSN puede instrumentar para realizar pagos o controlar cumplimientos de éstos, es preciso decir que en el presente proceso judicial Prevención ART S.A no puede ser condenada a los pagos de la sentencia en ninguna de las hipótesis posibles (ni directa ni solidariamente) pues no ha sido demandada, no es continuadora de Interacción ART SA y tampoco la referida concesión administrativa de "gerenciadora" le reviste de tal "status jurídico" respecto a las prestaciones dinerarias de pago único (cfr. Pliego de Bases y Condiciones emitido por la SSN).

- En cambio, por la participación invocada y concedida en este proceso, sí le incumbe a Prevención ART S.A, realizar todas las gestiones administrativas propias de tal "gerenciamiento" para efectivamente lograr la cancelación de los créditos que son admitidos por esta resolución. Frente a esta obligación de hacer que asumió en la causa y en caso de verificarse incumplimientos en esa "gestión gerencial" (en la etapa de ejecución de sentencia) se hace saber a Prevención ART SA, que a tales infracciones se le impondrán las sanciones procesales que las mismas acarrean según las normas contenidas en la L.C.T., ley 24.557 (y sus reglamentaciones), el C.C.C.N. y el C.P.C.C. de Cba. (por remisión del art. 114).

\section{Condena a la SSN}

En “Cufrém1, el Dr. Buté, vocal de la Sala Primera de la Cámara Única del Trabajo (CUT), en una causa contra la aseguradora liquidada Liderar SA resuelve "condenar únicamente a la Superintendencia de Seguros de la Nación". 
Para resolver en tal sentido brinda los siguientes argumentos:

-A partir del 1 de julio de 2016 se advierte la existencia de una nueva resolución, obrante bajo el No. 39910 adjudicando a Prevención A.R.T. SA sólo el gerenciamiento en las prestaciones tanto en especie como dinerarias para atender al fondo de reservas de la LRT, como de igual modo se le asigna intervenir en todo planteo judicial o extrajudicial conforme las condiciones y responsabilidades especificadas por la Superintendencia de Seguros de la Nación que obran impuestas en la Licitación Pública Nro. 17/2015, que en el segundo párrafo establece explícitamente lo siguiente: "Cuando se deban abonar indemnizaciones en concepto de Incapacidad Laboral Permanente Parcial Definitiva de pago único; muerte o incapacidad laboral total definitiva, la ART contratada remitirá el cálculo correspondiente a ésta SSN-Gerencia Administrativa-Sector fondo de reserva- para su consideración y posterior trámite del anticipo de fondos a través de la Tesorería de éste Organismo a favor de la ART contratada.

-El texto es prístino en cuanto a que Prevención ART SA no asumió en ningún momento el pago directo de las obligaciones dinerarias generadas por la Aseguradora liquidada. Ergo, no puede resultar alcanzada por los efectos de la presente condena. Siendo un extremo no controvertido que la acción fue direccionada en contra de la ART Liderar SA y encontrándose la misma en estado de liquidación, la respuesta debe darla entonces exclusivamente la Superintendencia de Seguros de la Nación, en consonancia con lo preceptuado por el art. 34 de la LRT y como Administradora del Fondo de reserva.

\section{Condena a la SSN y a la gerenciadora (Prevención ART SA)}

En "Barrionuevo"12, el Dr. Giletta (Sala $1^{\circ}$, CUT, Córdoba), determina que la obligación de pago incumbe a la Superintendencia de Seguros de la Nación en su calidad de Administradora del fondo de reserva y a Prevención ART SA en su condición de gerenciadora y representante en el proceso, para que con afectación exclusiva de dicho fondo (esto es, no con su propio patrimonio) procedan a abonar la indemnización. Además, dispone, por un lado, que la eventual insuficiencia de disponibilidad dineraria en el fondo de reserva deberá ser comunicada previo al vencimiento del plazo de pago y acreditarse de manera fehaciente, así como comunicarse los términos previstos para su recomposición y cancelación de la deuda. Y, por otro lado, que la orden impuesta a Prevención ART SA se entiende condicionada a su permanencia en calidad de gerenciadora y gestora de las prestaciones a cargo del fondo de reserva por contratación de la SSN, debiendo en el supuesto contrario acreditar la extinción del vínculo contractual, lo que se tramitará por las vías del art. 31 LPT, así como la eventual contratación de otra aseguradora para dicho rol, con el debido contradictorio.

En relación al obligado al pago frente el trabajador el tribunal analiza la situación de ART Liderar SA, deudora de la reparación. Así establece que a partir del proceso de liquidación las prestaciones serán asumidas a través del FdR, y que mediante resolución N³9910/2016 del 1 de julio de 2016, que se renovó luego mediante resolución Nº $311 / 2019$, la SSN dispuso aprobar la contratación de una aseguradora para gerenciar el otorgamiento de las prestaciones en especie y dinerarias que le correspondieren atender al FDr. Y remarca: "Se advierte que en el pliego...que fija las condiciones contractuales, se diferencia el tratamiento del pago de las prestaciones dinerarias de pago MENSUAL por incapacidad laboral transitoria, provisoria y gran invalidez, que deben ser afrontados directamente por la ART contratada con cargo del referido fondo y sujetas a reembolso, y de las

12 CUT, Córdoba, Sala $1^{\circ}$, sent. N 92, 17/05/2021, "Barrionuevo c/ Liderar ART SA", Dr. Ricardo Agustín Giletta. 
prestaciones de pago único que previo el trámite allí previsto, son anticipadas por la SSN a la ART para que proceda a su cancelación. ...Ello supone que en casos como el de autos, concernientes a una indemnización de pago único por ILP, la SSN debe proveer a su gerenciadora, Prevención ART SA, de los fondos necesarios para que proceda al pago, no siendo exigible de esta manera a esta aseguradora abonar y luego repetir, por no estar prevista esta mecánica para la indemnización en debate.

En “Monserrat"133, la Dra. Moreno (Vocal de la CUT, Córdoba, Sala $5^{\circ}$ ), resuelve condenar solidariamente a la Superintendencia de Seguros de la Nación y a Prevención a abonar la indemnización correspondiente.

Para fundamentar la decisión recurre a los siguientes argumentos:

"-La Aseguradora de Riesgos del Trabajo Liderar SA se encuentra en proceso de liquidación. En consecuencia, fue inhabilitada para actuar en juicio. ... compareció ... Prevención ART SA, designada como gerenciadora del fondo de reserva conforme lo dispuesto por el art. 34 ley 24.557. Así las cosas, conforme el sistema legal creado a partir del art. 34 LRT, es indudable la responsabilidad de esta última entidad en tanto es la administradora del cumplimiento de las prestaciones de la ley 24.557 que deben ser soportadas por el fondo que debe hacerse cargo de esta condena.

"-Si está a cargo de la Superintendencia de Seguros de la Nación, la administración del fondo de reserva creado por el art. 34 LRT para abonar o contratar las prestaciones a cargo de la ART que ésta no pudiera abonar como consecuencia de su liquidación, es clara la conclusión acerca de su responsabilidad en el pago de la reparación que se ordena.

"-Por otra parte, Prevención ART SA afirmó que carece de legitimación pasiva para ser condenada en los términos de la LRT. Además -argumenta- así surge de la resolución 39.910/2016 donde se aprueba la licitación $N^{\circ}$ 17/2015, de cuyo texto surge que no es continuadora de la ART, ni obligada directa. Al respecto, este Tribunal decide acatar el criterio del Tribunal Superior de Justicia aplicado por Sent. Número Dos del 18.02.2015 en autos: "SORIA Fabián Alfredo C/ LUZ A.R.T. SA - Ordinario-Despido- Enfermedad" Recurso de Casación-73.372/37", entre otros, donde dijo: "Luego, el capital, los intereses indicados y las costas deberán ser abonados por "Prevención A.R.T. SA" como mandataria de la Superintendencia de Seguros de la Nación que es administradora del fondo de reserva del art. 34 inc. $1^{\circ}$ L.R.T.- Sin perjuicio de las acciones que entre ellos pudieran existir fundadas en el contrato que luce a fs.180/184." Ello así por cuanto, el alto cuerpo entendió que Prevención ART SA a través de su participación como representante y mandataria de la SSN era la encargada de satisfacer la acreencia que surgía de la condena en los referidos actuados, con la salvedad apuntada.

"En la resolución 32762/08 de la SSN que dio origen a dicho decisorio y que aprobó la Adenda suscripta entre Prevención ART SA, como contratada, y la SSN como contratante, se estableció en la cláusula $8^{\circ}$ textualmente: "Acuerdan las partes que las sumas de dinero que por orden judicial deban abonarse o depositarse judicialmente en concepto de capital, intereses, honorarios de los profesionales reclamantes, y honorarios de peritos oficiales, sea por sentencias definitivas o medidas cautelares serán proporcionadas por la contratante (SSN) a solicitud de la contratada. En casos de urgencia y previa autorización por escrito de la contratante podrá la contratada cancelar dichos conceptos debiendo reintegrar la contratante los mismos". Esas eran las condiciones existentes al momento de dictarse la sentencia del Tribunal Superior de Justicia. 
"En tanto que en la actual resolución 39.910/16, invocada por Prevención ART SA, según el texto de la licitación 17/2015 en la parte pertinente indica: "Prestaciones dinerarias: Dentro del plazo de 15 (quince días de haberse completado la documentación, la ART contratada deberá efectuar las liquidaciones correspondientes las que deberá someter a consideración de la SSN -Gerencia Administrativa- Sector fondo de reserva. En el caso de corresponder la atención de prestaciones dinerarias de pago mensual por ILT e Incapacidad permanente parcial/total provisoria y Gran invalidez, previa conformidad de esta Superintendencia, efectuará el pago de las mismas con cargo al referido fondo. Cuando se deban abonar indemnizaciones en concepto de ILP parcial definitiva de pago único, muerte o incapacidad laboral total definitiva, la ART contratada remitirá el cálculo correspondiente a ésta SSN -Gerencia Administrativa- Sector fondo de reservapara su consideración y posterior trámite del anticipo de fondos a través de la Tesorería de este Organismo a favor de la ART contratada para proceder al pago de las mismas.

"Analizados el contenido y sentido de ambas resoluciones se verifica que en lo sustancial los efectos ante terceros no se han modificado. Las diferencias entre las dos regulaciones citadas atañen a condiciones a las que se someten las partes contratantes a fin de cumplir el cometido regulado en el art. 34 y cc LRT. No se han dispuesto nuevas condiciones hacia los terceros que hagan variar la conclusión a la que arribó el TSJ en el precedente señalado ("Soria").

"En la anterior resolución -como se ha visto en su transcripción- la SSN contrató a Prevención ART SA, y era la SSN quién debían proporcionar los fondos para el pago, lo mismo que se establece en la actual contratación, de tal suerte que la postura de la gerenciadora no es de recibo y debe ser condenada, sin perjuicio de las acciones que puedan tener entre sí con la SSN quien debe atender el crédito de este juicio a través del fondo de reserva.

"Por lo tanto, las responsables al pago de la prestación que se ordena en autos son la Superintendencia de Seguros de la Nación porque es la administradora del fondo de reserva creado por ley para el cumplimiento de las obligaciones de las aseguradoras liquidadas en forma solidaria junto con Prevención ART SA por haber asumido la responsabilidad de garantizar el pago de las prestaciones de la ley. Todo ello sin perjuicio de las acciones que entre ellos pudieran existir fundadas en el contrato que las vincula".

\section{Condena a la gerenciadora (Prevención ART SA) como mandataria de la SSN}

Este criterio -coincidente con el consolidado por el TSJ en los precedentes analizados "Soria", "Alvarez" $y$ "Rosales", entre otros, es el que mayoritariamente siguen las salas de la Cámara del Trabajo de la ciudad de Córdoba.

Sala 1: El Dr. Rolón, en "Quinteros ${ }^{14 ", ~ d i s p o n e ~ q u e ~ c o r r e s p o n d e ~ c o n d e n a r ~ a l ~ p a g o ~ d e l ~}$ capital e intereses a Prevención ART SA, en su carácter de administradora del fondo de reserva.

Sala 2: Ambos Vocales siguen el criterio del TSJ expuesto. El Dr. Requena, en "Villarreal15", y la Dra. Díaz, en "Pérez"16", disponen que ante la liquidación de la ART, la obligada al pago es la aseguradora Prevención ART SA como mandataria de la Superintendencia de Seguros de la Nación, en su carácter de administradora del fondo de reserva del art. 34 , inc. $1^{\circ}$, LRT.

\footnotetext{
14 CUT, Córdoba, Sala 1º, sentencia N 93, 17/05/2021, “Quinteros c/ ART Interacción S.A.”, Dr. Enrique A. M. Rolón.

15 CUT, Córdoba, Sala $2^{\circ}$, sent. $N^{\circ} 12,14 / 02 / 2018$, “Villarreal c/ ART Interacción SA”, Dr. Cristian Requena.

16 CUT, Córdoba, Sala $2^{\circ}$, sent. № 76, 12/08/2020, “Pérez c/ ART Liderar”, Dra Silvia Díaz.
} 
Sala 4: Ambos Vocales siguen el criterio del TSJ. El Dr. Marionsini, en "Camarada17", y el Dr. Zunino, en "Bustos"18", disponen condenar a Prevención ART SA, como gerenciadora designada por la SSN y en su carácter de administradora del fondo de reserva (art. 34 LRT), y con independencia de las acciones que entre ellas pudieren existir en función al contrato de gerenciamiento.

Sala 50: El Dr. Manzanares, en "Sette 19 ", sigue el criterio "Soria" del TSJ. Argumenta que entendió el alto cuerpo que Prevención ART SA a través de su participación como representante y mandataria de la SSN era la encargada de satisfacer la acreencia que surgía de la condena. En tal sentido, dispone condenar a Prevención ART SA (en su carácter de mandataria de la Superintendencia de Seguros de la Nación -administradora del fondo de reserva del art. 34 inc. $1^{\circ}$ LRT-y sin perjuicio de las acciones que entre ellos pudieran existir fundadas en el contrato que las vincula).

El Dr. Ferreyra en "Pedrocca"20" condena a Prevención ART SA (en su carácter de mandataria de la Superintendencia de Seguros de la Nación -administradora del fondo de reserva del art. 34, inc. $1^{\circ}$, LRT-y sin perjuicio de las acciones que entre ellos pudieran existir fundadas en el contrato que las vincula). Sigue el criterio del TSJ en "Soria".Frente al planteo de Prevención ART SA, gerenciadora del FdR, que afirma que no es parte del proceso, de modo que no puede ser condenada, el tribunal determina que analizados el contenido y sentido de la resolución 32762/08 de la SSN (con las condiciones existentes al momento de dictarse la sentencia del TSJ en "Soria") con la actual 39.910/16 invocada por Prevención ART SA resultan similares en lo sustancial. De tal manera, entiende que no se verifican nuevas disposiciones que hagan variar la conclusión a la que arribó el TSJ en el precedente señalado ("Soria"), pues también en la anterior resolución la SSN contrató a Prevención ART SA, y era la SSN quién debían proporcionar a Prevención, los fondos para que abonara, lo mismo que se establece en la actual contratación. En consecuencia, determina que Prevención ART SA debe ser condenada, sin perjuicio de las acciones que puedan tener, entre sí, con la SSN quien debe atender el crédito de este juicio a través del fondo de reserva.

Sala 7: El Dr. Bornancini, en "Núñez ${ }^{21 ", ~ c o n d e n a ~ a ~ l a ~ d e m a n d a d a, ~ P r e v e n c i o ́ n ~ A R T, ~ e n ~ s u ~}$ carácter de administradora del FdR, en virtud de la liquidación de ART Interacción SA

Sala 8: La Dra. Saracho Cornet, en "Gómezz2", condena a Prevención ART SA, en su condición de mandataria de la SSN (que es administradora del FdR, sin perjuicio de las acciones interpartes que el contrato respectivo establece). El Dr. Vega, en "Godoy23", condena a Prevención ART -en su condición de gerenciadora del FdR, administrado por la SSN-, a abonar al actor la prestación dineraria. Y en los fundamentos agrega que deja a salvo su derecho de repetir y/o requerir al FdR, los montos abonados. El Dr. Segura, en "Alberione 24 ", cita el precedente "Soria" del TSJ y condena a Prevención ART -en su condición de gerenciadora del FDr.

\footnotetext{
17 CUT, Córdoba, Sala $4^{\circ}$, sent. N 75, 03/05/2021, “Camarada c/ ART Liderar”, Dr. Mauricio Adrián Marionsini.

18 CUT, Córdoba, Sala $4^{\circ}$, sent. N 60, 14/04/2021, “Bustos c/ ART Liderar”, Dr. Angel Rodolfo Zunino.

19 CUT, Córdoba, Sala 5, sent. 134, 01/10/2020, “Sette c/ ART Liderar”, Dr. Julio Francisco Manzanares.

20 CUT, Córdoba, Sala 5, sent. N 105, 28/05/2021, “Pedrocca c/ ART Liderar”, Dr. Alcides Segundo Ferreyra

21 CUT, Córdoba, Sala $7^{\circ}$, sent. N 354, 30/07/2019, "Núñez c/ ART Interacción”, Dr. Arturo Bornancini.

22 CUT, Córdoba, Sala $8^{\circ}$, sent. N 95, 28/05/2021, “Gómez c/ ART Interacción”, Dra Teresita Nelly Saracho Cornet.

23 CUT, Córdoba, Sala $8^{\circ}$, sent. N 51, 22/04/2021, “Godoy c/ ART Liderar”, Dr. Jorge Alberto Vega.

24 CUT, Córdoba, Sala 8, sent. N ${ }^{\circ} 74,05 / 05 / 2021$, “Alberione c/ ART Interacción”, Dr. Sergio Oscar Segura.
} 
Sala 9: El Dr. Tosto, en "Villarrea/25", y la Dra. Ledesma, en "Oliva"26", condenan a Prevención ART, como mandataria de la SSN (administradora del FdR).

Sala 10: Ambos vocales siguen este criterio. En causas recientes, el Dr. Alberti, en "Altamirano 27", y el Dr. Saad, en "Burgos 28", disponen condenar a Prevencion ART SA (como mandataria de la SSN y sin perjuicio de las acciones que entre ellos pudieran existir).

Sala 11: La Dra. Garnero, en "Conti29", condena a Prevención ART en su carácter de mandataria de la SSN, administradora del FdR, en virtud de la liquidación de ART Interacción SA, a abonar al actor el monto de condena.

\section{La resolución 396/2020}

La resolución de la SSN N³96/2020 fue publicada en el Boletín Oficial con fecha $02 / 11 / 2020^{30}$. A la par que regla el procedimiento a seguir ante la falta de cumplimiento de una prestación ya sea dineraria o en especie por parte de una ART como consecuencia de encontrarse en estado de liquidación judicial, en el art. 1.2 contiene un "disposición conflictiva":

"1.2 La ART Gerenciadora no es deudora, ni se encuentra obligada a realizar anticipo alguno por las obligaciones a cargo del fondo de reserva, ya que su actuación se encuadra en la asistencia de siniestros y contingencias y de ningún modo el pliego licitatorio alude a las indemnizaciones derivadas de ello, las que se encuentra a cargo exclusivo y excluyente del fondo de reserva.

El fondo de reserva es el encargado de otorgar las prestaciones que una ART deje de brindar como consecuencia de su liquidación. La Gerenciadora no reviste carácter de continuadora de la ART en liquidación ni asume obligación alguna a cargo de aquella. La Gerenciadora no podrá ser considerada parte en los procesos judiciales en los cuales existan reclamos contra una ART en liquidación y por ende no puede ser objeto de condena ni medida cautelar alguna, preventiva o ejecutiva" (el resaltado nos pertenece).

\section{A. Su impacto en la jurisprudencia}

Hemos expuesto que la jurisprudencia mayoritaria considera que en los procesos judiciales contra las aseguradoras liquidadas el obligado al pago frente al trabajador es la ART gerenciadora.

Luego del dictado de la resolución 396/2020 que dispone que la gerenciadora no podrá ser considerada parte y no puede ser objeto de condena, el interrogante es cómo impacta dicha reglamentación en las decisiones judiciales en cuanto a la determinación del sujeto responsable de abonar las prestaciones impagas por la ART liquidada.

El Dr. Giletta (CUT, Córdoba, Sala 1²), en "Barrionuevo31", considera que "la norma puede

\footnotetext{
25 CUT, Córdoba, Sala 9, sent. $N^{\circ} 77,04 / 05 / 2021$, “Villarreal c/ ART Interacción”, Dr. Gabriel Alejandro Tosto.

26 CUT, Córdoba, Sala 9, sent. N 89, 14/05/2021, “Oliva c/ ART Liderar”, Dra Patricia Ledesma.

27 CUT, Córdoba, Sala $10^{\circ}$, sent. $N^{\circ} 46,07 / 05 / 2021$, “Altamirano c/ ART Liderar”, Dr. Huber Oscar Alberti.

28 CUT, Córdoba, Sala $10^{\circ}$, sent. $N^{\circ} 55,19 / 05 / 2021$, “Burgos c/ ART Interacción”, Dr. Horacio A. Saad.

29 CUT, Córdoba, Sala $11^{\circ}$, sent. N ${ }^{\circ} 53,03 / 05 / 2021$, “Conti c/ ART Interacción”, Dra Eladia Teresa Garnero.

30 Dispone sustituir el procedimiento del fondo de reserva creado por el art.34 de la ley $\mathrm{N}^{\circ} 24.557$ previsto en el artículo $8^{\circ}$ de la resolución RESOL-2018966-APN-SSN\#MHA, de fecha 21 de septiembre, por el que como Anexo IF-2020-73069057-APN-GA\#SSN forma parte integrante de la resolución. Dicho Anexo se titula "Procedimiento reglamentario del fondo de reserva".

31 CUT, Córdoba, Sala 1, sent. Nº 92, 17/05/2021, "Barrionuevo c/ Liderar ART SA”, Dr. Ricardo Agustín Giletta
} 
entenderse como complementaria o aclaratoria de la contratación vigente", y en virtud de ello concluye que "la obligación de pago incumbe a la SSN en su calidad de Administradora del fondo de reserva y a Prevención ART SA en su condición de gerenciadora y representante en el proceso para que con afectación exclusiva de dicho Fondo (esto es, no con su propio patrimonio) procedan a abonar la indemnización e intereses de condena".

En un trabajo de reciente publicación ${ }^{32}$, el referido camarista, al referirse a la resolución 396/2020 expone que a su criterio, "la cuestión de que la gerenciadora "no puede ser considerada parte en los procesos judiciales" debe ser interpretada en el sentido de que no es parte por derecho propio, sino en representación de la SSN; pero claramente debe tomar intervención en las causas en ese carácter". Por lo que, en definitiva, según su punto de vista "la obligada al pago de las prestaciones es la SSN, con afectación del fondo de reserva, sin perjuicio de la obligación de gestión que pesa sobre la gerenciadora, que puede ser monitoreada por el tribunal que hubiere dictado la condena, y aplicar en caso de incumplimiento sanciones pecuniarias".

La Dra. Garnero (CUT, Córdoba, Sala 11²), en "Conti33", resuelve desestimar el pedido de aplicación de la resolución 396/2000 efectuado por Prevención ART SA, con el argumento de que no estaba en vigencia ni a la fecha en que ocurriera el accidente, ni a la de interposición de la demanda.

Como fundamento de la decisión, la Dra. Fazio expone: "en su art. $2^{\circ}$ la norma bajo análisis dispone "La presente resolución entrará en vigencia desde la fecha de su publicación en el Boletín Oficial", lo que ocurrió el 02/11/2020. En cuanto a que la ART Gerenciadora no es deudora, ni se encuentra obligada a realizar anticipo alguno por las obligaciones a cargo del fondo de reserva, me remito al criterio sostenido por el Tribunal Superior de Justicia en autos "Colazo, Daniel Alberto c/Aseguradora de Riesgos del Trabajo Interacción SA - Ordinario - Accidente (ley de Riesgos) - Recurso de Casación" (Sent. No. 1, 04/02/2020), haciendo responsable del pago, tanto de la indemnización como de las costas del juicio, a Prevención ART SA, en su carácter de mandataria de la Superintendencia de Seguros de la Nación que es la administradora del fondo de reserva, sin perjuicio de las acciones que le pudiera corresponder a la aseguradora respecto de esta última. Destacó asimismo el máximo Tribunal que “... Prevención ART, al comparecer y tras explicar el procedimiento que sigue a la liquidación de una aseguradora, invoca la resolución de SSN No. 39.910/2016 y aclara que dispuesto la contratación de Prevención ART SA -precisamente- como "gerenciadora" del otorgamiento de las prestaciones a cargo del FDR, agregando que se extiende a los reclamos judiciales y prejudiciales. Luego, mas allá de los términos empleados por el a quo y de la forma de efectivizar los beneficios respecto de los cuales no hay discusión que recaen en el FDR-sea con bienes propios y luego acción de reembolso o directamente con recursos del FDR-, no surge que la obligación que se le impuso sea en una calidad distinta a la que la interesada invocó al pedir participación y a mérito de la cual se le acordó".

En consecuencia, resolvió desestimar el pedido de aplicación de la resolución 396/2000 y responsabilizar a Prevención ART S.A., dejando aclarado que dicha responsabilidad lo es en su carácter de mandataria de la SSN, administradora del FDr.

\footnotetext{
32 GILETTA, Ricardo Agustín, "El fondo de reserva de la ley 24.557. Cuestiones conflictivas en orden a su cobertura en los Procesos Judiciales", Revista Catorce Bis $\mathrm{N}^{\circ}$ 60, Editorial Copiar, Córdoba, AADTySS, 2021, p. 90,

33 CUT, Córdoba, Sala 11º, sent. N 53, 03/05/2021, “Conti c/ ART Interacción”, Dra. Eladia Teresa Garnero.
} 
La Dra. Moreno (CUT, Córdoba, Sala $5^{\circ}$ ), en "Monserrat"34", dispuso que "es improcedente el pedido de aplicación de la resolución de SSN 396/2020 por cuanto su vigencia comenzó el dos de noviembre de dos mil veinte y el hecho dañoso es de fecha once de mayo de dos mil dieciséis. Luego, en tanto esta normativa no tiene prevista una pauta de aplicación retroactiva, se deben seguir las directivas generales de aplicación de las leyes en el tiempo".

Por su parte, el Dr. Requena (CUT, Córdoba, Sala $2^{\circ}$ ), en "Basile 35 ", declara la inconstitucionalidad de la resolución 396/2020.

En dicha causa, Prevención ART SA había planteado la aplicación de la mencionada resolución dictada por la SSN. El tribunal consideró que correspondía examinar su constitucionalidad por entender que se inmiscuye en materia sustancial y adjetiva, pretendiendo reglar el art. 34 LRT, pero además, también sobre materia netamente procesal, lo cual extralimita aspectos expresamente no delegados por las provincias.

El Dr. Requena hace mención a que, a la fecha, existen decisorios ("Barrera, Juan Domingo c/ Liderar ART SA s/Accidente", sentencia del 26/05/2021, dictada por el magistrado Julio Gómez Orellano, de la Segunda Cámara del Trabajo de la Primera Circunscripción de Mendoza) que ya se han expedido y, a su criterio, sin necesidad de abordar el tema constitucional, refiriendo solamente a su inaplicabilidad por una razón básica de la aplicación de la ley en el tiempo, ya que esta resolución de la SSN, fue publicada en el Boletín Oficial con fecha 02/11/20, muy posterior a la fecha de la primera manifestación invalidante del caso.

Al respecto dice: "Obviamente, es principio liminar de nuestro derecho el de irretroactividad de las leyes, y si el legislador pretende su vulneración, debe ser expresamente contemplada en la propia norma y plenamente justificada, lo cual ni remotamente se aborda en esta mera resolución, de rango muy inferior a la ley. Si bien participo de la razonabilidad de este argumento, entiendo además que, por lo dicho respecto a que se inmiscuye en materia procedimental (y ésta sí es de aplicación inmediata en el tiempo), inevitablemente debe considerarse su adecuación constitucional. Adelanto, a los fines del desarrollo que efectúo a continuación, que considero que dicha norma es inconstitucional, y además, que corresponde declararla de oficio, porque se trata de una cuestión de puro derecho en donde la contradicción entre la norma superior -la ley-y la norma inferior -la mera resolución- que altera el texto expreso, es flagrante, por lo que debe imperar el deber de mantener la supremacía constitucional (art. 31 CN), aplicándose en caso de colisión de normas la de mayor rango, desechándose la de rango inferior".

Es posible sintetizar los fundamentos de lo resuelto por el Dr. Requena en los siguientes puntos:

- "Lo primero que debe indicarse es que en cuanto a las estipulaciones que contiene en el Anexo punto 1.2, en orden a que la gerenciadora no es deudora, conforma un enunciado no discutido y sobre el que ya hay pronunciamiento del T.S.J. de esta provincia y de la C.S.J.N., Tribunales que además ya han establecido los efectos de la participación de las gerenciadoras. No obstante, Ia S.S.N. avanza en su resolución estipulando que: "La Gerenciadora no podrá ser considerada parte en los procesos judiciales en los cuales existan reclamos contra una ART en liquidación y por ende no puede ser objeto de condena ni de medida cautelar alguna, preventiva o ejecutiva", lo que impone al Tribunal, el escrutinio constitucional de la decisión del

34 CUT, Córdoba, Sala 5², sent. N 62, 05/05/2021, “Monserrat c/ ART Liderar”, Dra Ana María Moreno.

35 CUT, Córdoba, Sala 2º sent. N 92, 01/06/2021, "Basile c/ ART Liderar SA”, Dr. Cristian Requena. 
organismo administrativo, a fin de mantener la jerarquía normativa de nuestro ordenamiento jurídico". El enunciado "invocando el art. 34 de la ley 24.557, pretende establecer directivas que avanzan sobre reglas de jerarquía superior (art. $31 \mathrm{CN}$ ) y sobre la praxis que esas reglas imponen a otro Poder del Estado, lo que constituye una extralimitación en sus facultades.

- "Del punto 1.2 de la resolución administrativa, surge explicito que al establecer que la gerenciadora que concurre a un proceso "no podrá ser considerada parte", pretende reglar nada menos que sobre materia no delegada al poder federal, desde que todo lo relativo a los sujetos que intervienen en un conflicto judicial, es materia, precisamente, de normas procesales y como tal, reservada a la potestad provincial. Es esta normativa, la que determina las reglas que rigen la conducta y actividad de los sujetos que intervienen en el proceso, los derechos, obligaciones y cargas.

- "Si bien en el ordenamiento no se verifica una conceptualización de la figura del gerenciamiento, no puede ser la S.S.N. quien determine su alcance y lo imponga a la jurisdicción, en detrimento de la regulación sustancial y procesal, y lo que es más grave aún, sometiendo al trabajador incapacitado a la consideración y voluntad del ente al cumplimiento de la condena. Luego, la resolución en examen no modifica lo ya analizado y que conforma criterio asumido por este Tribunal, el cual, es coincidente con el expuesto por TSJ en el citado precedente "Álvarez" $y$ en reiterados pronunciamientos dictados con posterioridad.

- "Si bien, respecto del concepto 'gerenciamiento', al no encontrarse definido en el ordenamiento común, se le suele asignar facultades organizativas y de gestión, cuando ingresa en el marco de un proceso debe necesariamente asumir el rol previsto en el ordenamiento formal, conforme la actividad que pretenda desarrollar, máxime si además, lo es en el marco del sistema de riesgos del trabajo en el cual expresamente se han determinado los sujetos que pueden intervenir en él.

- "Que mediante una decisión administrativa de un organismo nacional, se introduzca un sujeto no previsto en la normativa de riesgos del trabajo, y mediante otra decisión de igual carácter, se pretenda determinar los derechos, obligaciones y cargas que asumirá dentro del proceso reglado por normas provinciales, tal como lo autoriza la Constitución Nacional, no aparece razonable y menos aún ajustado a derecho. La S.S.N., en el marco de sus incumbencias, no se encuentra habilitada para legislar sobre el carácter que estas gerenciadoras deben asumir en un proceso, porque tal atribución corresponde, conforme los arts. 5 y 122 de la C.N., a las provincias en ejercicio de su competencia de determinar las normas que deben regir su sistema judicial; arrogarse estas facultades, violenta no solo la garantía federal reconocida a las provincias de dictar las normas que aseguren su administración de justicia, sino también la previsión consagrada en el art. 31 C.N., respecto de la jerarquía normativa. Luego, lo dispuesto en el punto 1.2., en tanto excede el marco de su incumbencia, violenta la normativa constitucional precedentemente señalada, pues asume facultades que inclusive constitucionalmente, están vedadas al Congreso de la Nación y al Ejecutivo Nacional."

Por dichos argumentos, considera que corresponde que se invalide la directiva 1.2 de la resolución 396/2020, con lo que dispone declararla inconstitucional. De tal modo, resuelve que la obligada al pago, ante la liquidación de ART Liderar SA, es la aseguradora Prevención ART SA como mandataria de la SSN, en su carácter de administradora del FdR del art. 34.1 de la ley 24.557. 


\section{Intereses}

La derogada resolución 414/99 (B.O., 17/11/1999) establecía que los créditos derivados de la LRT se actualizaban mediante la tasa activa del Banco de la Nación Argentina para descuento de documentos en adelante en adelante TA, criterio que fuera sustituido por la res. con. que estableció que, en caso de intervenir el FdR, el nuevo coeficiente de actualización será la tasa pasiva del Banco Central de la República Argentina, en adelante TPPBCRA, desde que la suma es debida por el fondo.

La modificación en las tasas de interés aplicables tuvo como fundamento preservar no sólo a los damnificados sino al universo de los trabajadores del sistema y que contemplara en forma equitativa tanto los intereses de los accidentados como los del FdR.

Dichos argumentos fueron atendibles en el marco temporal del dictado de la res. con. Sin embargo, analizada la evolución patrimonial del FdR y por sobre todo la ampliación del porcentaje de las primas que recibe, entendemos que dichos argumentos han perdido buena parte de su justificación.

Los datos relevados llevan a replantear si resulta justificable reducir intereses y/o excluir accesorios legales cuando interviene el FdR al advertir que la situación económico/financiera del mismo le permitiría abonar sin dificultades la totalidad de los créditos.

Finalmente, debe tenerse presente que se ha controvertido la competencia tanto de la SRT como de la SSN para establecer las tasas de actualización.

En efecto, la potestad asumida por los referidos entes no surge de las normas que regulan su creación o funcionamiento, y en función de que la competencia de los entes públicos es limitada y de excepción ${ }^{36}$ ha llevado a cierto sector de la doctrina a entender que la res. con. ha excedido la competencia funcional de los órganos que la dictaron ${ }^{37}$.

\section{Los intereses en la jurisprudencia de la provincia de Córdoba Metodología}

Se ha procurado mediante la reseña de distintos fallos, dictados por los distintos Vocales que integran las salas de la CUT de la ciudad de Córdoba, analizar los distintos criterios adoptados.

Debido a la extensión de la muestra y a la mutabilidad de las decisiones, la presente sistematización no pretende ser exhaustiva ni definitiva, sino mostrar los distintos criterios adoptados en un determinado momento.

\section{Criterios rectores}

Se han agrupado las decisiones de las distintas salas en base a tres criterios definidos como: a) Tasa "TPPBCRA", con más un 2\% mensual, b) TPPBCRA sin aditamentos, c) Tasas Sucesivas, que implica la aplicación de los criterios anteriores combinados.

\section{A. Precedentes de la Cámara Única del Trabajo}

\section{TPPBCRA + $2 \%$ Mensual}

A partir del dictado del precedente "Hernández c/ Matricería Austral" se entiende en forma

36 TSJ, Córdoba, Sala Contencioso Administrativa, 04/04/2007, "Shell Gas SA c/ Provincia de Córdoba".

37 GILETTA, Ricardo Agustín, ob. cit. p. 51. 
absolutamente mayoritaria, que los créditos laborales se actualizan a razón de TPPBCRA + 2 Mensual, desde que cada suma es debida.

Esta fórmula se ha aplicado también a créditos originados como consecuencia de infortunios laborales, e incluso cuando ha intervenido el FDr.

En este sentido, se registran tres precedentes de la Sala $7^{\circ}$ de la CUT, donde se ratifica la aplicación de este criterio.

En la causa "Núñez ${ }^{38 ", ~ r e s u e l t a ~ p o r ~ e l ~ D r . ~ B o r n a n c i n i, ~ s e ~ c o n d e n o ́ ~ a l ~ F d R ~ a ~ a c t u a l i z a r ~ e l ~}$ monto de las prestaciones dinerarias mediante TPPBCRA + 2\% mensual desde la primera manifestación invalidante hasta el efectivo pago. En idéntico sentido, "Aliendo39" y "Marsi$\| i^{40 "}$ resueltos ambos por el Dr. Rugani.

Finalmente, en la causa "Barrionuevo 41" la Dra. Mimessi, con la particularidad de que los accesorios tienen como fecha de inicio la demanda.

\section{TPPBCRA}

A partir del dictado del precedente "Soria ${ }^{42 "}$ dictado por el TSJ a principios del 2015, la mayoría de los Vocales de las Salas de la CUT han seguido el criterio sentado en dicho decisorio, actualizando las prestaciones dinerarias a razón de la TPPBCRA sin aditamento, desde la interposición de la demanda.

En este sentido, pueden reseñarse los siguientes precedentes agrupados por Salas:

En la Sala $2^{\circ}$, en los autos "Villarreal43" " “Camacho ${ }^{44 "}$ los Dres. Requena y Díaz aplicaron el presente criterio. Sin embargo, a partir del dictado de sentencia en "Pacheco45" " "Ferreyra ${ }^{46 "}$ los citados magistrados adoptan el tercer sistema de actualización por tasas sucesivas. Por su parte, la Sala $3^{\circ}$ registra decisorios en este sentido en los autos "Tobares ${ }^{47}$ ", dictado por la Dra. Galloppo.

Tanto la Sala $4^{\circ}$ en los autos: "Tassara 48 " y "Villarreal49", como la Sala 60 in re "García ${ }^{50 ",}$ "Barrera ${ }^{51 "}$ " "Rojas ${ }^{52 ",}$ han aplicado este sistema; al igual que los Dres. Alberti y Saad integrantes de la Sala $10^{\circ}$, in re "Lozano53" $y$ "Burgos ${ }^{54 ",}$ aunque recientemente el último

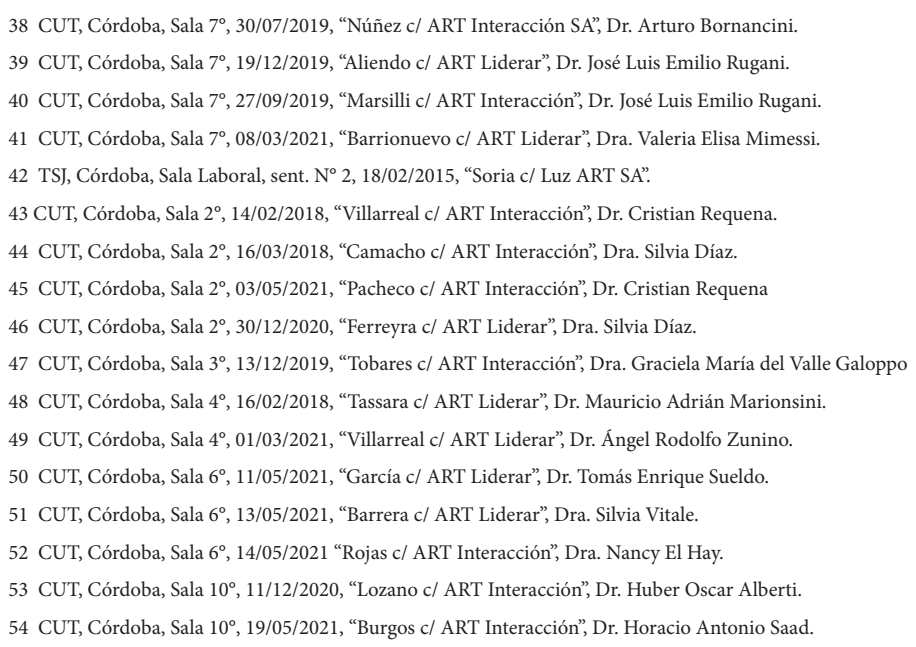


magistrado modificara su criterio a partir de los autos "Perafán ${ }^{55 ", ~ s e g u ́ n ~ l o s ~ p a r a ́ m e t r o s ~}$ del precedente " $D$ 'Angelo5" del Tribunal Superior.

Por su parte, las salas $11^{\circ}$ y $8^{\circ}$ entendieron aplicable este criterio in re "Borguetti57", "Calderón $n^{58 " ~ y ~ " A l b e r i o n e ~}{ }^{59 " ;}$; aunque recientemente la Dra. Saracho Cornet modificó su opinión mediante en "Gómez" ${ }^{\circ 0}$, adoptando el criterio del TSJ en "D 'Angelo".

Finalmente, en la causa "Villarreal61", el Dr. Tosto ha aplicado el presente criterio, con la salvedad de que el punto de partida para el cálculo de los intereses ha sido la primera manifestación invalidante y no la interposición de la demanda.

\section{Tasas sucesivas}

El presente criterio consiste en aplicar dos tasas diferenciadas de intereses a lo largo del periodo que transcurre entre la primera manifestación invalidante y el efectivo pago de la acreencia.

Es así como, desde la primera manifestación invalidante o desde la demanda se aplica la TPPBCRA con el aditamento del $2 \%$ mensual hasta la fecha de liquidación de la Aseguradora, momento a partir del que se aplicará la tasa de intereses contemplada en la res. con., es decir, TPPBCRA sin aditamento.

Este criterio reconoce precedentes jurisprudenciales anteriores inclusive al dictado del precedente "D 'Angelo", como por ejemplo "Jiménez ${ }^{62 " . ~}$

A partir del decisorio del TSJ citado, la jurisprudencia de las CUT ha ido paulatinamente adhiriendo a este criterio, advirtiéndose a la fecha que siguen este criterio tanto el Dr. Buté como el Dr. Rolón, ambos de la Sala $1^{\circ}$ en los autos "Cufre ${ }^{63 "} y$ "Spera ${ }^{64 " .}$

La Sala $2^{\circ}$ aplica el referido criterio, lo que se verifica en los autos: "Pacheco65", "Ochoa 6 " y el ya citado precedente "Jiménez".

Asimismo, adopta esta modalidad el Dr. Provensale (CUT, Córdoba, Sala $3^{\circ}$ ), en "Maldonado ${ }^{67 " . ~ L a ~ D r a . ~ S a r a c h o ~ C o r n e t ~(C U T, ~ C o ́ r d o b a, ~ S a l a ~} 8^{\circ}$ ), en la causa "Gómez ${ }^{68 "}$ y el Dr. Saad (CUT, Córdoba, Sala $10^{\circ}$ ), en "Perafán ${ }^{69 ", ~ a u n q u e ~ d e b e n ~ t e n e r s e ~ p r e s e n t e ~ l a s ~ c i r c u n s t a n-~}$ cias particulares del último fallo reseñado donde la sentencia de fondo es anterior a la li-

\footnotetext{
55 CUT, Córdoba, Sala 10, 17/03/2021, "Perafán c/ ART Liderar”, Dr. Horacio Antonio Saad.

56 TSJ, Córdoba, Sala Laboral, sent. N 286, 15/12/2020, "D’ Angelo c/ ART Liderar SA”.

57 CUT, Córdoba, Sala 8, 30/07/2018, "Borghetti c/ ART Interacción”, Dr. Jorge Alberto Vega.

58 CUT, Córdoba, Sala 8, 17/03/2021, “Calderón c/ ART Interacción”, Dra. Teresita Saracho Cornet.

59 CUT, Córdoba, Sala 8 , 05/05/2021, "Alberione c/ ART Interacción", Dr. Sergio Oscar Segura

60 CUT, Córdoba, Sala 8, 28/05/2021, “Gómez c/ ART Interacción”, Dra. Teresita Saracho Cornet.

61 CUT, Córdoba, Sala 9, 04/05/2021, "Villarreal c/ ART Interacción”, Dr. Gabriel Tosto.

62 CUT, Córdoba, Sala 2, Auto № 41, 25/06/2020, “Jiménez c/ ART Liderar”, Dr. Luis Fernando Farías

63 CUT, Córdoba, Sala $1^{\circ}, 15 / 04 / 2021$, “Cufré c/ ART Liderar”, Dr. Victor Hugo Buté.

64 CUT, Córdoba, Sala 1 , 08/04/2021, "Spera c/ ART Liderar”, Dr. Enrique A. M Rolón.

65 CUT, Córdoba, Sala 2 , 03/05/2021, "Pacheco c/ ART Interacción”, Dr. Cristián Requena.

66 CUT, Córdoba, Sala 2º 04/04/2021, “Ochoa c/ ART Liderar”, Dra. Silvia Díaz.

67 CUT, Córdoba, Sala 3², 28/05/2021 "Maldonado c/ ART Liderar”, Dr. Federico Guillermo Provensale.

68 CUT, Córdoba, Sala 8, 28/05/2021, "Gómez c/ ART Interacción”, Dra. Teresita Saracho Cornet.

69 CUT, Córdoba, Sala 10, 17/03/2021, “Perafán c/ ART Liderar”, Dr. Horacio Antonio Saad.
} 
quidación de la aseguradora y la planilla de determinación de montos es posterior a la misma.

Los Dres. Godoy y Ledesma (CUT, Córdoba, Sala $9^{\circ}$ ), registran decisorios en este sentido en las causas "Salguero" ${ }^{70 "}$ "Oliva"

Finalmente, deben destacarse los decisorios de los Dres. Giletta, Manzanares, Moreno y Ferreyra quienes, con criterios propios, adoptan sistemas de tasas sucesivas, aunque con parámetros diferentes a los señalados.

Así el Dr. Giletta, integrante Sala $1^{\circ}$, aplica un criterio consistente en TPPBCRA desde la primera manifestación invalidante hasta la liquidación de la aseguradora y luego aplica tasa activa promedio del BCRA, lo que se verifica en los autos "Padilla $a^{72 ", ~ e n t e n d i e n d o ~ q u e ~}$ la res. con. es inconstitucional.

La Sala $5^{\circ}$ adopta dos criterios distintos. El Dr. Manzanares actualiza las prestaciones dinerarias mediante RIPTE y luego aplica TPPBCRA, según lo determinado en autos: "Set$t e^{73 \prime}$. Los restantes camaristas (Moreno y Ferreyra) actualizan las prestaciones mediante la aplicación del RIPTE y un interés anual del 15\%, según los parámetros fijados en "Monserrat ${ }^{74 "} y$ "Pedrocca ${ }^{75 "}$ ".

\section{B. Evolución de los criterios del Tribunal Superior de Justicia}

El primer antecedente provincial referido a las tasas de interés aplicables cuando interviene el FdR se dicta con fecha 18/02/2015 en la causa "Soria" estableciendo la aplicación de la res. con. y, por ende, la actualización de los créditos mediante TPPBCRA, en este caso desde la interposición de la demanda.

Este criterio fue seguido por numerosos fallos entre los que se destacan "Álvarez" "Pattacini"7".

El cimero tribunal toma en cuenta en sus considerandos que deben aplicarse intereses diferenciados, en este caso más bajos, cuando interviene el FdR recurriendo al concepto de justicia distributiva al entender que: "... todas las leyes que legislan los estados falenciales, encuentra explicación -como antes se mencionara- en la protección de todos los que necesitan cobrar créditos por igual. Se supera así, cualquier alternativa individualista, más aún cuando se trata de personas laboralmente enfermas o accidentadas. De otro modo, se pone en peligro el cobro efectivo de la indemnización a que se hizo lugar...".

Esta forma de cálculo de los intereses se mantuvo invariable hasta finales del año 2020 cuando se dictaron numerosos fallos referidos a ART que actualizaron los criterios interpretativos.

\footnotetext{
70 CUT, Córdoba, Sala 9, 11/05/2021, "Salguero c/ Art Interacción”, Dr. Daniel J. Godoy

71 CUT, Córdoba, Sala 9, 14/05/2021 “Oliva c/ Liderar”, Dra. Patricia Mariana Ledesma.

72 CUT, Córdoba, Sala 1², 26/03/2021, “Padilla c/ ART Liderar”, Dr. Ricardo Agustín Giletta.

73 CUT, Córdoba, Sala 5 ${ }^{\circ}, 01 / 10 / 2020$, "Sette c/ ART Liderar", Dr. Julio Francisco Manzanares.

74 CUT, Córdoba, Sala 5, 05/05/2021, "Monserrat c/ ART Liderar, Dra Ana María Moreno.

75 CUT, Córdoba, Sala 5², 28/05/2021, "Pedrocca c/ ART Liderar", Dr. Alcides Segundo Ferreyra.

76 TSJ, Córdoba, Sala Laboral, sent. N ${ }^{\circ} 16,04 / 03 / 2015$, "Álvarez c/ Responsabilidad Patronal ART".

77 TSJ, Córdoba, Sala Laboral, sent. №6, 11/02/2020, "Pattacini c/ ART Interacción".
} 


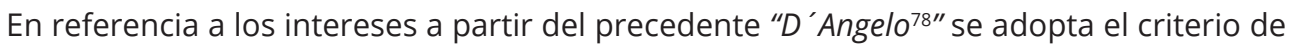
tasas sucesivas.

Durante el tramo inicial de los intereses, comprendido entre la primera manifestación invalidante y la resolución que dispone la liquidación de la aseguradora, se aplica TPPBCRA con más un adicional del $2 \%$ mensual.

El segundo tramo, comprendido entre la resolución que dispone la apertura del proceso liquidatorio hasta el efectivo pago, se actualiza mediante TPPBCRA.

EI TSJ justifica la modificación de los precedentes a los fines de "mantener incólume el contenido económico del crédito, en virtud del tiempo transcurrido entre esta última (liquidación forzosa) y la demanda-26/03/12-. A lo que se suma, la naturaleza del reclamo -daño a la salud".

Esta postura fue ratificada en sucesivos fallos: "Álvarez" ${ }^{79 "}$, asimismo, aunque con matices en "Marchetti80" $y$ "Verrúa ${ }^{81 " .}$

En los dos últimos decisorios, se toma como punto de inflexión entre las tasas aplicables, la declaración de quiebra de la aseguradora, lo que podría generar inconvenientes con la aplicación práctica, debido a que las ART se encuentran excluidas del proceso concursal contemplado en la ley 24.522 (B.O. 09/08/1995), en función de que no son sujetos concursables ${ }^{82}$.

Los antecedentes jurisprudenciales del TSJ no agotan las hipótesis que pueden presentarse, sobretodo cuando la primera manifestación invalidante se produce luego de la sanción de la ley 27.348 y/o DNU 669/19, supuestos donde entrarían en conflicto la TPPBCRA con el adicional del $2 \%$ aplicable antes de la hipotética liquidación de una aseguradora; asimismo la tasa activa contemplada en las referidas normas colisionan con la TPPBCRA contemplada en la res. con.

\section{Las costas ¿forman parte de los conceptos integrativos de la eventual condena?} Resulta relevante distinguir las soluciones judiciales suscitadas antes y después del dictado del decreto $\mathrm{N}^{\circ} 1022 / 17^{83}$. Antes del dictado del referido decreto, no existían dudas en el alcance de la obligación de pago con los montos del FdR, es decir, eran mandados a pagar capital histórico, intereses y costas.

EI TSJ, en "Álvarez"84 y "Amoroso85", entre otras sentencias, determinó que Prevención ART SA debía abonar dichos conceptos, en su calidad de mandataria de la SSN, administradora del FdR, sin perjuicio de las acciones que entre ellas pudieran existir. Similar decisión

\footnotetext{
78 TSJ, Córdoba, Sala Laboral, sent. N²86, 15/12/2020, "D’ Ángelo c/ ART Liderar SA".

79 TSJ, Córdoba, Sala Laboral, sent. N 112, 04/05/2021, "Álvarez c/ ART Interacción".

80 TSJ, Córdoba, Sala Laboral, sent. N ${ }^{\circ} 14,24 / 02 / 2021$, "Marchetti c/ ART Interacción".

81 TSJ, Córdoba, Sala Laboral, sent. № 94, 27/04/2021, "Verrua c/ ART Interacción".

82 JUNYENT BAS, Francisco y MOLINA SANDOVAL, Carlos A., "Ley de Concursos y quiebras comentada”, Ed. Lexis Nexis - Depalma, Buenos Aires, 2003, T1, p. 51

83 Decreto $\mathrm{N}^{\circ}$ 1022/17 (BO 11/12/2017).

84 TSJ, Córdoba, Sala Laboral, sent. N 16, 04/03/2015, "Álvarez c/Responsabilidad Patronal".

85 TSJ, Córdoba, Sala Laboral, sent. N ${ }^{\circ}$ 17, 04/03/2015, “Amoroso c/ Responsabilidad Patronal ART".
} 
se adoptó en el Plenario "Borgia"8" de la Cámara Nacional de Apelaciones del Trabajo (en adelante, CNAT), con la salvedad que en esta resolución se refería al alcance de la responsabilidad de la SSN.

El decreto $\mathrm{N}^{\circ} 1022 / 17$, sustituyó al art.22 del decreto $\mathrm{N}^{\circ} 334 / 96$, reglamentario de varias normas de la LRT. El referido art. 22, reglamenta al art. 34 de la LRT (fondo de reserva). En su texto original el art. 22 disponía que:

"El fondo de reserva no responderá por las prestaciones derivadas de los servicios que las Aseguradoras se encuentran habilitadas a contratar conforme al artículo 26 apartado 4 de la ley sobre Riesgos del Trabajo.".

A su turno, el apartado 4, del art. 26 establece que:

"Las ART podrán, además, contratar con sus afiliados: a) El otorgamiento de las prestaciones dinerarias previstas en la legislación laboral para los casos de accidentes y enfermedades inculpables; $y, b)$ La cobertura de las exigencias financieras derivadas de los juicios por accidentes y enfermedades de trabajo con fundamento en leyes anteriores. Para estas dos operatorias la ART fijará libremente la prima, y llevará una gestión económica y financiera separada de la que corresponda al funcionamiento de la LRT. Ambas operatorias estarán sometidas a la normativa general en materia de seguros.".

Es decir, el FdR no fue previsto para cubrir la cobertura que las ART contrataren con sus afiliados y fueran relativas a accidentes y enfermedades inculpables y las indemnizaciones emanadas de los juicios por accidentes y enfermedades de trabajo con fundamento en leyes anteriores. El FdR solamente cubría las prestaciones dinerarias y en especie del sistema de riesgos del trabajo.

El art.1 del decreto $n^{\circ}$ 1022/17, sustituyó la norma prevista en el art. 22 del decreto $n^{\circ}$ 334/96 con el siguiente texto:

"La obligación del fondo de reserva alcanza al monto de las prestaciones reconocidas por la ley $N^{\circ} 24.557$ y sus modificatorias, excluyéndose las costas y gastos causídicos. El fondo de reserva no responderá por las prestaciones derivadas de los servicios que las Aseguradoras de Riesgos del Trabajo se encuentran habilitadas a contratar conforme al artículo 26, apartado 4, de la ley sobre Riesgos del Trabajo ni por las indemnizaciones que se reconozcan con fundamento en el derecho común.".

La norma reglamentaria cambió sustancialmente su contenido, incorporó dos aspectos más que no serían pasibles de cobertura por el FdR: a) las indemnizaciones que se reconozcan con fundamento en el derecho común -lo cual es lógico, ya que solo cubre prestaciones del sistema tarifado- $y$, b) las "costas y gastos causídicos"; es decir, excluyó de la cobertura los honorarios de letrados y peritos judiciales, tasas de justicia, aportes profesionales, inmiscuyéndose en competencias no delegadas por las provincias a la Nación y alterando el sentido de la norma de fondo (LRT) por la vía reglamentaria, lo cual es discutible en su constitucionalidad.

X. Costas: Evolución de la jurisprudencia del TSJ y de la CUT de Córdoba (2015/2021) La ausencia expresa en la norma de fondo y en la reglamentaria Las primeras ART liquidadas fueron Luz y Responsabilidad Patronal. Los tribunales de 
mérito, al dictar sentencias favorables a las demandas interpuestas, o al imponer las costas, se las imponían a las referidas aseguradoras, independientemente si ya habían comparecido a juicio las ART gerenciadoras designadas por la SSN. Ello era motivo de recurso de casación, y en el año 2015 el TSJ dictó una serie de fallos donde fijó su criterio: las costas debían ser soportadas por Prevención ART (gerenciadora).

En pocas palabras, en "Amarfil/7" el TSJ dispuso que: "La exclusión de las costas no surge del texto legal, por lo que la interpretación del recurrente, deviene interesada". Idéntica solución tuvo en otros pronunciamientos de esa época ${ }^{88}$.

En otras causas, con una pequeña diferencia en la redacción determinó que: "Respecto a la exclusión de las costas por no surgir del texto legal, el pedido deviene inadmisible por infundado ${ }^{89 "}$.

Es decir, la postura del TSJ se fundaba en imponer las costas a la "mandataria" de la SSN, administradora del FdR, en la ausencia de una norma que expresamente excluya a las costas de los gastos a afrontar con el fondo.

\section{Aplicación de la ley en el tiempo. El decreto 1022/17 1. Cámara Única del Trabajo}

La sanción del decreto $N^{\circ} 1022 / 17$ produjo un simbronazo interpretativo en los tribunales cordobeses. Conforme la posición asumida por el TSJ antes de que el decreto entrara en vigor, la existencia de una norma que excluya las costas de las obligaciones a asumir por el FdR, debía necesariamente conducir a que los tribunales la apliquen.

En ese momento, las causas existentes contra ART Interacción, liquidada en agosto de 2016, fueron las que generaron múltiples interpretaciones; las cuales se pueden reunir en 3 grupos:

a) Salas que aplicaron el decreto 1022/17: Algunos Vocales de la CUT de Córdoba, aplicaron el criterio del Tribunal Superior, pero contrario sensu. Es decir, al existir una norma que dispone la exclusión de las costas de las obligaciones a cubrir por el fondo, corresponde aplicarla y ordenar que estas sean reclamadas ante el proceso liquidatorio. El Dr. Braín, ex vocal de la Sala 10, en la causa "Fusari90", dispuso que: "Conforme lo dispuesto por el art. 1 del decreto 1022 de fecha 11 de diciembre de 2017, que modifica el art. 22 del decreto 334 del 1 de abril de 1996, la obligación del fondo de reserva alcanza al monto de las prestaciones reconocidas por la ley $N^{\circ} 24.557$ y sus modificatorias, excluyéndose las costas y gastos causídicos".

b) Salas que declararon inaplicable el decreto 1022/17: Otros camaristas, utilizando el criterio de aplicabilidad de la ley en el tiempo, consideraron que el decreto no era aplicable a ART Interacción; esto, en tanto, su liquidación judicial ocurrió en agosto de 2016 y la publicación del decreto 1022 fue el 11/12/2017.

87 TSJ, Sala Laboral, sent. N 11, 19/02/2015 "Amarfil c/Responsabilidad Patronal".

88 TSJ, Sala Laboral, sent. N ${ }^{\circ}$ 17, 04/03/2015, “Amoroso c/Responsabilidad Patronal”; sent. N 36, 11/03/2015, "Irrazabal c/Responsabilidad Patronal”; sent. $\mathrm{N}^{\circ} 37,11 / 03 / 2015$, "Juncos c/Responsabilidad Patronal"; sent. N² 269, 03/11/2015, "Albano c/Responsabilidad Patronal” y sent. N 72, 05/07/2016, "Ortega c/Responsabilidad Patronal".

89 TSJ, Sala Laboral, sent. N 16, 04/03/2015, "Álvarez c/Responsabilidad Patronal” y sent. No 83, 26/03/2015, "Álvarez c/Responsabilidad Patronal”. 90 CUT, Córdoba, Sala 10, sent. Nº 214, 12/06/2018, “Fusari c/ ART Interacción”, Dr. Daniel Brain. 
El Dr. Zunino (CUT, Córdoba, Sala 4), en la causa "Rosales"91", determinó que: "A todo evento cabe precisar que este tribunal no desconoce lo dispuesto por el decreto 1022/2017... Ello claramente implica que los honorarios de los letrados y peritos, así como los demás gastos del juicio, no deben ser afrontados por el mencionado fondo... Sin embargo el decreto... no resulta de aplicación al caso de autos, toda vez que en su art. 3 dispone: "La presente medida entrará en vigencia a partir del día siguiente al de su publicación en el Boletín Oficial". En consecuencia es claro que la norma en cuestión no será aplicable a los supuestos de aseguradoras liquidadas con antelación a su publicación en el BO, como es el supuesto de autos. Esta solución, o sea que las leyes de fondo rigen para lo futuro, fue ratificada por el alto cuerpo nacional (CSJN, "Espósito c/ Provincia", del 7/06/2016) y también provincial (TSJ, "Martín c/ Mapfre", del 22/02/2014). Por lo expresado corresponde declarar inaplicable al presente caso el decreto 1022/2017".

c) Salas que declararon inconstitucional el decreto 1022/17: Un último grupo de jueces, evitaron la discusión de la aplicabilidad de la norma en el tiempo y consideraron que la norma era inconstitucional por exceso reglamentario, en tanto alteraba la norma del art. 34 LRT.

Tal es el ejemplo del voto de la Dra. Saracho Cornet en "Reartes ${ }^{92 "}$ donde la Sala $8^{\circ}$ resuelve rechazar -por mayoría- una apelación de la ART designada por la SSN para que la represente en las causas judiciales: "Desde lo formal, al regular el régimen de las costas y los intereses, el decreto 1022/17 ha excedido el marco constitucional (cfr. art. 99 inc. 2) claro y determinante en orden a la naturaleza del dispositivo reglamentado. Desde lo sustancial: Existe una evidente afectación del derecho a la jurisdicción del trabajador dado que al excluir a los letrados que lo asisten de cobrar sus estipendios de la parte vencida (y en el caso del fondo de reserva) resulta evidente que lo que se está provocando es que, o el trabajador quede sin la asistencia letrada que elige, o bien que detraiga una porción de indemnización -que tiene que ver con la reparación del daño a su salud-para atender los honorarios de su letrado, aun siendo ganancioso en el pleito...".

\section{Tribunal Superior de Justicia}

A raíz de la disparidad de criterios en las distintas salas de la Cámara Única del Trabajo de Córdoba, se incrementaron los recursos de casación e inconstitucionalidad ante el TSJ, tanto de la parte actora, sus letrados -por derecho propio-, los letrados de la ART liquidada y de Prevención ART.

La situación expuesta derivó que en el año 2019 el alto cuerpo provincial dictara dos autos interlocutorios, por los cuales rechazó los recursos de casación interpuestos por Prevención ART, que requería la aplicación del decreto 1022/17. El alto cuerpo, a través de la expresión "situación fáctica", también utilizó el criterio de la "aplicación de la norma en el tiempo" y declaró inaplicable al mencionado decreto reglamentario a la liquidación de ART Interacción. Los casos fueron "Monzón" y "Rosales":

"Monzón" ${ }^{93 "}$ fue resuelto por la Sala $11^{\circ}$, a través del voto de la exvocal, Dra. Bonetto, previo a la sanción del decreto, por lo tanto condenó en costas a Prevención, con cargo del fondo de reserva. EI TSJ dispuso que: "La exclusión de las costas que persigue el impugnan-

91 CUT, Córdoba, Sala $4^{\circ}$, sent. $\mathrm{N}^{\circ}$ 67, 26/03/2018, “Rosales c/ ART Interacción”, Dr. Angel R. Zunino

92 CUT, Córdoba, Sala $8^{\circ}$, AI N ${ }^{\circ}$ 58, 17/04/2018, "Reartes c/ REX Argentina SA y otro".

93 TSJ, Sala Laboral, AI N 154, 30/04/2019, “Monzón c/ ART Interacción”. 
te, no surge del texto legal del decreto al que alude - $n^{\circ} 334 / 96-$, por lo que la interpretación que desarrolla deviene interesada (en igual sentido de esta Sala Sents. $n^{\circ} 2 / 15,269 / 15$, entre otras). No modifica dicha conclusión el hecho de que a la fecha el decreto $n^{\circ}$ 1022/17 -del 11/12/2017- efectúa esa disquisición de manera expresa, pues la situación fáctica que determina la normativa aplicable es anterior a su vigencia".

"Rosales94" fue el caso mencionado anteriormente, resuelto por la Sala $4^{\circ}$, a través del voto unipersonal del Dr. Zunino. El TSJ confirmó la decisión del a quo, y en lo referido al decreto expresó que: "Lo propio ocurre en relación a la exclusión de las costas que persigue. El sentenciante, explicó -con acierto- que si bien el decreto No 1022/17 -del 11/12/17- efectúa esa disquisición de manera expresa, atento a lo dispuesto en su art. 3: "La presente medida entrará en vigencia a partir del día siguiente al de su publicación en el Boletín Oficial", es inaplicable a los supuestos de aseguradoras liquidadas con antelación a su publicación, como ocurre en el subexamen. Señaló, que tal solución es conteste con las directrices del Máximo Tribunal expuestas en la causa "Espósito c/ Provincia ART SA" (del 07/06/16). De ello se sigue que, el Juzgador basó el criterio de aplicabilidad en el tiempo, justamente, en la situación fáctica que determina la puesta en funcionamiento del FDR-liquidación de una ART-, en consonancia con lo resuelto por el Máximo Tribunal de la Nación. Por lo tanto, las manifestaciones del recurrente sólo reflejan una interpretación alternativa e interesada tanto del nuevo decreto $N^{\circ}$ 1022/17, como del art. 34 LRT y del decreto N³34/96 que no resulta idónea para evidenciar el error jurídico que denuncia".

\section{XI. ¿Y ahora qué? Los criterios de la Cámara del trabajo luego del dictado de "Mon- zón" y "Rosales" por el TSJ. La liquidación de ART Liderar}

Las resoluciones dictadas por el TSJ, en relación a la sanción del decreto 1022/17 y la doctrina de la aplicabilidad de la ley en el tiempo, trajeron cierto orden en relación a las causas donde la demandada era ART Interacción.

Por lo tanto, la solución jurídica -para aquellos tribunales que imponían las costas a ART Interacción-, era la inaplicabilidad de la norma; al ser la liquidación temporalmente anterior a la entrada en vigencia del decreto.

De alguna manera, la solución brindada por el alto cuerpo provincial trajo 2 lecturas posibles: a) el decreto es constitucional y, por lo tanto, aplicable para las ART que sean liquidadas luego de la sanción de la modificación reglamentaria; o b) la discusión sobre la inconstitucionalidad de la norma será tratada en el caso de que otra ART sea liquidada a posteriori de la sanción del decreto.

Estas lecturas se plasmaron en lo que sucedió en el año 2019, concretamente el 07/10/19, ART Liderar fue liquidada judicialmente. Por lo tanto, el debate jurisdiccional acerca de la aplicabilidad del decreto 1022/17 volvió a abrirse.

Otra posible controversia se dio en relación a la terminología utilizada por el TSJ cuando resolvió "Monzón" y "Rosales", es decir la "situación fáctica" del TSJ. Ya que si uno lee ambas resoluciones, pero sobre todo "Rosales", esa situación fáctica hace expresa referencia la liquidación judicial de la ART. No obstante ello, algunos Vocales de Cámara ampliaron el abanico de opciones para usar la terminología a la: 1) "fecha de la primera 
manifestación invalidante" (en adelante, PMI), y 2) "fecha de la interposición de la demanda". Esta ampliación surgió también a partir de la liquidación de ART Liderar.

Por ello, existieron cuatro escenarios en las resoluciones judiciales:

\section{A. Inaplicabilidad de la norma en los juicios en contra de ART Interacción:}

Varios Vocales de Cámara siguieron el criterio del TSJ en "Monzón" y "Rosales"y declararon inaplicable el decreto 1022/17, ordenando a la SSN o a la ART gerenciadora a asumir las costas del pleito. Por ejemplo, la Dra. Galoppo (CUT, Córdoba, Sala 3), en "Tabares95": "En cuanto a las costas, en el presente, el Tribunal aplica el criterio fijado por el Excmo. Tribunal Superior de Justicia de la Provincia en autos "Rosales"... las costas serán a cargo del fondo de reserva administrado por la Superintendencia de Seguros de la Nación, a través del gerenciamiento de Prevención ART SA -art. 28 de la ley 7.987-, a excepción de las generadas por la intervención de los peritos de control, que resultan a cargo de sus proponentes."

\section{B. Inaplicabilidad de la norma en los juicios en contra de ART Liderar:}

Otros Vocales, en las causas en contra de ART Liderar, ampliaron el criterio de la "situación fáctica" adoptado por el Tribunal Superior y declararon inaplicable el decreto 1022/17 por ser la fecha de la PMI, o la de la interposición de la demanda, anteriores a la sanción del decreto y ordenaron a la SSN o a la ART gerenciadora asumir las costas. Tal es el caso del Dr. Buté (CUT, Córdoba, Sala 1), en "Cufré96": "Las costas devengadas en este proceso son a cargo de la SSN (art. 28 CPT), con excepción de los emolumentos de los peritos de control que serán soportados por sus respectivos proponentes (art. 49, ley 9459)... el decreto 1022/17 no resulta aplicable al presente diferendo, ya que la demanda data del 13 de agosto de 2012, es decir que se trata de un proceso judicial que fue iniciado hace muchos años, con anterioridad a su vigencia. De manera que se erige en una suerte de celada procesal que los profesionales intervinientes deban, repentinamente, transitar otras jurisdicciones y otros fueros, apartándolos del juez natural de la causa, en aras de percibir sus legítimas acreencias que revisten carácter alimentario".

\section{Aplicabilidad de la norma en los juicios en contra de ART Liderar:}

Por lo general, aquellos Vocales que aplicaban el decreto antes del dictado de las resoluciones del TSJ, siguieron con el criterio de la "aplicabilidad" para las causas en contra de ART Liderar, ello en tanto, la "situación fáctica" es posterior a la vigencia de la norma reglamentaria. Una de ellas es la Dra. Silvia Vitale (CUT, Córdoba, Sala 6), en "Cabral"977: "Respecto de las costas corresponde imponerlas a la liquidada ART LIDERAR SA, con excepción de las generadas por Prevención ART SA, ello de conformidad a lo dispuesto por el art. 22 del decreto 1022/2017 y decreto $N^{\circ} 334 / 1996$ y al criterio jurisprudencial sustentado por la Sala Laboral de nuestro TSJ en autos "Rosales" y "Monzón"... y la fecha de liquidación de la ART aludida, el día 7/10/2019... con lo cual contrario sensu, por la fecha de liquidación de la demandada, rige la exclusión aquí dispuesta. Importa aclarar, que la suscripta modificó la posición asumida en anteriores pronunciamientos, siguiendo el criterio sustentado por la Sala Laboral del TSJ, no sólo por razones de economía procesal y ante la función nomofiláctica del alto cuerpo Provincial, sino porque lo allí resuelto obligó a un nuevo análisis de la cuestión en examen, sosteniendo la inaplicabilidad del decreto 1022/2017, a situaciones anteriores a su vigencia, como la de marras".

\footnotetext{
95 CUT, Córdoba, Sala 3ㄹ sent. № 426, 16/12/2019, “Tobares c/ ART Interacción”, Dra. Graciela María del Valle Galoppo.

96 CUT, Córdoba, Sala $1^{\circ}$, sent. $N^{\circ} 20,22 / 03 / 2021$, “Cufré c ART Liderar”, Dr. Víctor Hugo Buté.

97 CUT, Córdoba, Sala $6^{\circ}$, sent. № 280, 30/12/2020, “Cabral c/ ART Liderar”, Dra. Silvia Vitale.
} 


\section{Inconstitucionalidad el decreto 1022/17}

Por otro lado, aquellos tribunales que declararon la inconstitucionalidad del decreto continuaron con su criterio sin entrar en las disyuntivas acerca de qué ART liquidada era la demandada en la causa. Un ejemplo de esto es el voto de la Dra. Díaz (CUT, Córdoba, Sala $2^{\circ}$ ) en "Marengo98": "Respecto de las costas, Prevención ART SA solicita la aplicación del decreto 1022, dictado el 12/12/2017... Este Tribunal tiene dicho en reiterados pronunciamientos... que, en atención al principio iura novit curia, el Tribunal tiene el deber de mantener la supremacía de la Constitución Nacional (Art 31 CN) y considerando lo dispuesto por la CSJN en "Banco Comercial Finanzas SA", corresponde examinar la adecuación constitucional de la norma cuya aplicación se pretende. Al respecto esta Sala Segunda... en integración unipersonal del doctor Cristián Requena en autos "Villarreal"... Sentencia $N^{\circ} 12$, del 14/02/2018... Este Tribunal en tanto comparte el criterio y los fundamentos expresados los asume, atento que el análisis efectuado por el doctor Requena expone argumentos suficientes y eficientes para mostrar la ausencia de adecuación del precepto contenido en el Art. 1 del decreto 1022/2017, a las claras directivas contenidas en los Arts. 31, 5, 121 y 99 inc. 2 de la CN, y por derivación, los Arts. 34, Ap. 2 de la ley 24.557 y 28 CPT. Consecuente con el desarrollo efectuado, corresponde declarar la inconstitucionalidad de la norma en análisis, la que por tal motivo no resulta aplicable al sub examen. Conforme lo manifestado precedentemente, Prevención ART SA, deberá cumplir en el carácter señalado, con las costas impuestas a Aseguradora de Riesgos Liderar SA, con excepción de las generadas por los profesionales que actuaron en representación de la Aseguradora liquidada, que serán a su cargo".

\section{EI TSJ y la inconstitucionalidad del decreto 1022/17}

Como se expresó en los títulos anteriores, la liquidación de ART Liderar volvió a provocar un sinnúmero de resoluciones judiciales, ellas fueron organizadas en los 4 grupos referidos. Todo indicaba que el tratamiento concreto de la validez constitucional del decreto 1022/17 iba a ser resuelta con una causa con ART Liderar como demandada. Sin embargo, el TSJ -en pleno- tomó una causa en contra de ART Interacción ("Fusari") con un recurso de inconstitucionalidad interpuesto por la actora a raíz de que el exvocal de la Sala $10^{\circ}$, Dr. Braín, resolvió que las costas serían afrontadas por ART Interacción. Es decir excluyó las costas de la obligación de pago con el fondo de reserva. La sentencia recurrida fue dictada el 12/06/2018, antes de los precedentes del TSJ en "Rosales" y "Monzón".

EI TSJ, en pleno, consideró que la norma infralegal cuestionada altera al art. 34 LRT a reglamentar, por ello resulta inconstitucional. Nuevamente la intención del alto cuerpo fue, a partir de su función nomofiláctica, establecer un quietus a la diversidad de criterios existente. Para el caso concreto consideró que los honorarios de los letrados de la parte actora debían ser abonados con importes provenientes del fondo de reserva; los honorarios de los letrados de la ART liquidada, reclamados a la liquidación de la aseguradora.

Los párrafos destacados del fallo "Fusari99", son los siguientes:

"De conformidad con el criterio de esta Sala Laboral, en orden a la aplicación del decreto de que se trata, esto es que no comprende la declaración de quiebra anterior a su vigencia, no surgiría evidente, en el subexamen, el agravio concreto. Sin embargo, planteada su inconstitucionalidad y con el fin de evitar mayores dilaciones que terminan afectando, aún más los tiempos del proceso, resulta necesario un pronunciamiento que traiga un quietus a la jurisprudencia contradictoria en la materia".

98 CUT, Córdoba, Sala 2ª auto N² 201, 15/12/2020, “Marengo c/ ART Liderar”, Dra. Silvia Díaz.

99 TSJ, Córdoba, Pleno, sent. Nº66,30/03/2021, "Fusari c/ ART Interacción”. 
"Se adelanta opinión en el sentido de que el interesado, por la parte actora, demuestra la colisión del dispositivo reglamentario con la norma fundamental, causándole un perjuicio de imposible reparación ulterior. Es cierto, que la Constitución del año 1994, resuelve a favor de la dinámica de la potestad reglamentaria. El sistema dual, ya sea que el poder administrador actúe residualmente, como en el presente caso o lo haga de manera supletoria, encuentra limitación en la propia realidad. Que, en los términos de la ley Máxima, significa no alterar el espíritu de la ley a la que coadyuva, ya que debe facilitar su aplicación, sin quebrar su finalidad-arg. art. 28 C.N.-. En autos, aplicado el decreto en crisis, no se cargan costas al fondo de reserva porque así lo dispone, aspecto que no estaba en la norma primaria. De ahí, el exceso del ejecutivo -inc. $2^{\circ}$, art. 99 ib.- claramente disvalioso para los derechos del impugnante, quien terminará pagando los gastos causídicos que no alcancen a ser cubiertos por la distribución que se lleve a cabo en la quiebra... Ahora bien, superaría la razonabilidad de esta decisión, que las costas por la intervención de la aseguradora, que hoy es deudora insolvente recayeran también sobre el fondo de reserva, las que se pagarán por su representada. Por lo expuesto y habiendo dictaminado la Fiscalía General..., corresponde, declarar la inconstitucionalidad del decreto $N^{\circ} 1022 / 17$, con el alcance expresado... se admite el recurso deducido por la parte actora, exceptuando las costas de "Interacción ART SA', las que serán a su cargo".

\section{Cámara Única del Trabajo de Córdoba}

¿Logró el TSJ el "quietus" pretendido luego del fallo "Fusari"? La respuesta es sí. Finalmente, desde el mes de abril del 2021, e independientemente de cuál ART liquidada sea la demandada en juicio, todos los Vocales de la Cámara Única del Trabajo de Córdoba ordenan que las costas del pleito, a excepción de los honorarios de los letrados de la aseguradora liquidada, deben ser afrontadas con los importes del FdR.

Más allá que "Fusari" solamente declarara inconstitucional el decreto en relación a que los honorarios de los letrados de la parte actora sean excluidos de los importes que debe abonar el FdR, las salas incluyen la totalidad de las costas, a excepción de los honorarios de los letrados de la ART liquidada.

Va a modo enunciativo un fallo por cada uno de los actuales Vocales de las once salas de la Cámara Única del Trabajo de Córdoba ${ }^{100}$ :

Sala 10: A) El Dr. Giletta, en "Barrionuevo101", consideró inconstitucional al decreto 1022/17, criterio que ya había adoptado antes de "Fusari". Expresó que: "Las costas deben ser afrontadas por el fondo de reserva y no por la liquidación de la ART, salvo los honorarios de los letrados de la ART liquidada y Prevención ART". Un dato particular del vocal es que en el concepto "prestaciones" a cubrir por el FdR incluye las "complementarias" (honorarios de letrados, peritos, aportes y servicio de justicia). B) El Dr. Rolón, en "Spera102", declara inaplicable al decreto 1022/17. Utiliza el criterio de la "situación fáctica" amplia, ya que la PMI del actor, era anterior a la entrada en vigencia del decreto. En su resolución cita "Fusari". C) El Dr. Buté, en "Velarde Aguedas ${ }^{103 ", ~ a l ~ i g u a l ~ q u e ~ e l ~ D r . ~ R o l o ́ n, ~ d e c l a r a ~ i n a p l i c a b l e ~}$ al decreto 1022/17, por ser la PMI anterior a la entrada en vigencia del decreto; también cita "Fusari" (TSJ SN 66/21).

\footnotetext{
$100 \mathrm{Al}$ menos, hasta el relevamiento hecho a principios del mes de junio/2021.

101 CUT, Córdoba, Sala $1^{\circ}$, sent N ${ }^{\circ}$ 92, 17/05/2021, “Barrionuevo c/ ART Liderar”, Dr. Ricardo Agustín Giletta.

102 CUT, Córdoba, Sala $1^{\circ}$, auto N ${ }^{\circ}$ 43, 08/04/2021, “Spera c/ ART Liderar”, Dr. Enrique A. M. Rolón.

103 CUT, Córdoba, Sala $1^{\circ}$, sent Nº 74, 29/04/2021, "Velarde Aguedas c/ ART Liderar", Dr. Víctor Hugo Buté.
} 
Sala $2^{\circ}$ : Ambos vocales mantienen su criterio de inconstitucionalidad del decreto 1022/17 a partir de "Villarrea/104" dictada por el Dr. Requena. A) Éste, en "Pacheco105", mantiene su criterio de inconstitucionalidad, agrega una cita a "Fusari". B) La Dra. Díaz, en "Pérez ${ }^{106 ",}$ cita los fundamentos de Requena en "Villarreal". Agrega cita a "Rosales"y "Monzón" del TSJ. En "Ochoa 107", cita "Fusari" en un auto que deniega la concesión del recurso de casación a Prevención ART.

Sala 30: A) El Dr. Provensale, en "Maldonado108", cambia su criterio de aplicabilidad del decreto a las ART liquidadas a posteriori de su sanción. Cita "Fusari", dejando a salvo su postura. B) La Dra. Galoppo, en "Coman"109", declara la inconstitucionalidad y cita a "Fusari".

Sala 4": Ambos vocales cambian de criterio a partir de "Fusari". En las causas contra Liderar, donde antes aplicaban la norma, ahora la declaran inconstitucional. A) El Dr. Marionsini, en "Camarada110". B) El Dr. Zunino, en "Bustos"11".

Sala $5^{\circ}$ : Los tres vocales mantienen su criterio de inconstitucionalidad fijado a partir de "Albornoz"112". A) El Dr. Manzanares, en "Sette113". B) La Dra. Moreno, en "Monserrat"14". C) El Dr. Ferreyra, en "Pedrocca115".

Sala $6^{\circ}$ : La Sala en pleno cambió su criterio de aplicabilidad del decreto a los casos donde la demandada es ART Liderar, ahora declara la inconstitucionalidad. A) La Dra. Vitale, en "Barrera116". B) El Dr. Sueldo, en "García117". C) La Dra. El Hay, en "Rojas"118".

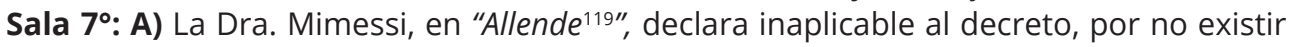
norma en la LRT que limite la responsabilidad del fondo de reserva. Refiere a la primera doctrina del TSJ en los juicios contra Responsabilidad Patronal. B) El Dr. Rugani no tiene sentencias post "Fusari"; pero en "Barú Guerrero"120" declaró la inconstitucionalidad del decreto cuando la PMI es anterior a la entrada en vigencia de la norma, cita a "Rosales". C) El Dr. Bornancini, tampoco tiene sentencias post "Fusari", pero en "Núñez"121", declaró inaplicable el decreto, conforme "Rosales".

Sala 8: A) La Dra. Saracho Cornet, en "Gómez"122", mantiene su postura de inconstitucionalidad del decreto, expuesta en "Reartes" y agrega cita a "Fusari". B) El Dr. Vega, en "Godoy 123", mantiene su postura de inconstitucionalidad expuesta también al resolver la apelación en "Reartes" (Auto N 58/18), agrega cita a "Fusari". C) El Dr. Segura, en "Alberio-

\footnotetext{
104 CUT, Córdoba, Sala 2, sent N 12, 14/02/2018, “Villarreal c/ ART Interacción”, Dr. Cristián Requena. 105 CUT, Córdoba, Sala $2^{\circ}$, sent N 53, 03/05/2021, “Pacheco c/ ART Interacción”, Dr. Cristián Requena. 106 CUT, Córdoba, Sala $2^{\circ}$, sent $N^{\circ} 76,12 / 08 / 2020$, “Pérez c/ ART Liderar”, Dra. Silvia Díaz. 107 CUT, Córdoba, Sala 2ª auto Nº 69, 08/04/2021, “Ochoa c/ ART Liderar”, Dra. Silvia Díaz. 108 CUT, Córdoba, Sala 3º, sent. Nº 93, 28/05/2021, "Maldonado c/ ART Liderar”, Dr. Federico Guillermo Provensale. 109 CUT, Córdoba, Sala 3º sent. Nº 90, 21/05/2021, “Coman c/ ART Liderar”, Dra. Graciela María del Valle Galoppo 110 CUT, Córdoba, Sala $4^{\circ}$, sent. N ${ }^{\circ} 75,03 / 05 / 2021$, “Camarada c/ ART Liderar”, Dr. Mauricio Adrián Marionsini 111 CUT, Córdoba, Sala $4^{\circ}$, sent. Nº 60, 14/04/2021 “Bustos c/ ART Liderar”, Dr. Angel Rodolfo Zunino. 112 CUT, Córdoba, Sala 5, sent. N 309, 27/07/2018, “Albornoz c/ ART Interacción”, Dr. Julio Francisco Manzanares 113 CUT, Córdoba, Sala 5, sent. N 134, 01/10/2020, “Sette c/ ART Liderar”, Dr. Julio Francisco Manzanares. 114 CUT, Córdoba, Sala 5º sent. $N^{\circ}$ 62, 05/05/2021, “Monserrat c/ ART Liderar”, Dra. Ana María Moreno 115 CUT, Córdoba, Sala $5^{\circ}$, sent. N 105, 28/05/2021, “Pedrocca c/ ART Liderar”, Dr. Alcides Segundo Ferreyra. 116 CUT, Córdoba, Sala 6º sent. N 132, 13/05/2021, "Barrera c/ ART Liderar" Sala 6º, Dra.Silvia Vitale. 117 CUT, Córdoba, Sala 6º sent. N 125, 11/05/2021, “García c/ ART Liderar”, Dr. Tomás Enrique Sueldo 118 CUT, Córdoba, Sala 6º sent. Nº 132, 14/05/2021, "Rojas c/ ART Interacción”, Dra. Nancy N. El Hay. 119 CUT, Córdoba, Sala $7^{\circ}$, sent. Nº 57, 11/05/2021, “Allende c/ ART Liderar”, Dra. Valeria E. Mimessi. 120 CUT, Córdoba, Sala 7º, sent. N 106, 13/07/2020, "Barú Guerrero c/ ART Liderar”, Dr. José Luis Emilio Rugani. 121 CUT, Córdoba, Sala $7^{\circ}$, sent. $N^{\circ} 354,30 / 07 / 2019$, "Núñez c/ ART Interacción”, Dr. Arturo Bornancini. 122 CUT, Córdoba, Sala 8, sent. N 95, 28/05/2021, “Gómez c/ ART Interacción”, Dra. Teresita Nelly Saracho Cornet. 123 CUT, Córdoba, Sala $8^{\circ}$, sent. N 51, 22/04/2021, “Godoy c/ ART Liderar”, Dr. Jorge Alberto Vega
} 
$n e^{124 ",}$ cambia su criterio minoritario expuesto en "Reartes" y declara inconstitucional al decreto, aplicando así el criterio de la mayoría de su Sala.

Sala 9: A) El Dr. Tosto, en "Villarreal125", declaró al decreto inaplicable, refiere a "Rosales" y "Monzón" del TSJ. B) El Dr. Godoy, en "Salguero126", también declaró al decreto inaplicable y citó a "Fusari". C) La Dra. Ledesma, en "Oliva"27", declaró inaplicable al decreto y refirió al criterio del TSJ en "Monzón".

Sala 10: Ambos vocales cambiaron su criterio -dejándolo a salvo- en las causas donde la demandada es ART Liderar. A) El Dr. Alberti, en "Altamirano 128". B) El Dr. Horacio A. Saad, en "Burgos"129".

Sala 11: La Dra. Garnero, previo a Fusari, en "Flores' ${ }^{130 ", ~ d e c l a r o ́ ~ i n c o n s t i t u c i o n a l ~ e l ~ d e c r e-~}$ to 1022/17 y refirió al criterio del TSJ en "Monzón". Luego de "Fusari", en "Conti131", declaró inaplicable el decreto en las causas contra Interacción.

Aquí finaliza el análisis de la evolución jurisprudencial en materia de costas en los juicios en contra de una ART liquidada. La intención fue exponer la evolución de los criterios jurisprudenciales del TSJ y de las distintas salas de la CUT de Córdoba.

\section{Conclusiones}

A lo largo del presente se han abordado, a partir de la jurisprudencia cordobesa, la actuación procesal del FdR, el funcionamiento del referido fondo, así como las prestaciones accesorias que comprenden los créditos a satisfacer, en especial vinculados a intereses y costas.

En cuanto a la actuación procesal del FdR, resulta difícil dimensionar al día de la fecha en qué medida la irrupción de la resolución 396/2020 impactará en la jurisprudencia provincial. A pocos meses de su vigencia, son pocos los tribunales que la han considerado y desde ya queda expuesta la disparidad de criterios. Los conflictos interpretativos con cuestiones constitucionales involucradas han ocurrido con distintas reglamentaciones relacionadas al FDr. Ésta no parece ser la excepción. Respecto de la condena o no a la gerenciadora tras el dictado de la resolución 396/2020, deberemos esperar las próximas resoluciones de la CUT y del TSJ para evaluar su impacto en la jurisprudencia y evaluar cuál resulta ser el criterio que se consolida al respecto.

Por el contrario, en lo referente a las costas y en menor medida en cuanto a los intereses aplicables, la jurisprudencia tiende a unificarse a partir de los precedentes del TSJ, advirtiendose en los últimos meses una clara tendencia en este sentido.

\footnotetext{
124 CUT, Córdoba, Sala $8^{\circ}$, sent. N ${ }^{\circ} 74,05 / 05 / 2021$, “Alberione c/ ART Interacción”, Dr. Sergio Oscar Segura.

125 CUT, Córdoba, Sala 9, sent. N 77, 04/05/2021, “Villarreal c/ ART Interacción”, Dr. Gabriel Alejandro Tosto

126 CUT, Córdoba, Sala 9, sent. N 81, 11/05/2021, "Salguero c/ ART Interacción”, Dr. Daniel Jorge Godoy.

127 CUT, Córdoba, Sala $9^{\circ}$, sent. N 89, 14/05/2021, “Oliva c/ ART Liderar”, Dra. Patricia Ledesma

128 CUT, Córdoba, Sala $10^{\circ}$, sent. N ${ }^{\circ}$ 46, 07/05/2021, “Altamirano c/ ART Liderar”, Dr. Huber Oscar Alberti

129 CUT, Córdoba, Sala 10, sent. N 55, 19/05/2021, “Burgos c/ ART Interacción”, Dr. Horacio A. Saad.

130 CUT, Córdoba, Sala 11 ${ }^{\circ}$, auto N ${ }^{\circ} 30,23 / 03 / 2021$, “Flores c/ ART Liderar”, Dra. Eladia Teresa Garnero.

131 CUT, Córdoba, Sala $11^{\circ}$, sent. N ${ }^{\circ}$ 53, 03/05/2021, “Conti c/ ART Interacción”, Dra. Eladia Teresa Garnero.
} 